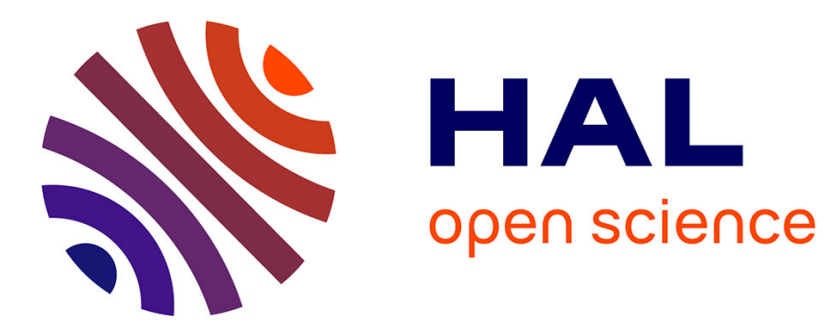

\title{
Demographics in MENA countries: a major driver for economic growth
}

Yeganeh Forouheshfar, Najat El Mekkaoui, Hippolyte d'Albis

\section{To cite this version:}

Yeganeh Forouheshfar, Najat El Mekkaoui, Hippolyte d'Albis. Demographics in MENA countries: a major driver for economic growth. 2019. halshs-02409029

\section{HAL Id: halshs-02409029 \\ https://shs.hal.science/halshs-02409029}

Preprint submitted on 13 Dec 2019

HAL is a multi-disciplinary open access archive for the deposit and dissemination of scientific research documents, whether they are published or not. The documents may come from teaching and research institutions in France or abroad, or from public or private research centers.
L'archive ouverte pluridisciplinaire HAL, est destinée au dépôt et à la diffusion de documents scientifiques de niveau recherche, publiés ou non, émanant des établissements d'enseignement et de recherche français ou étrangers, des laboratoires publics ou privés. 


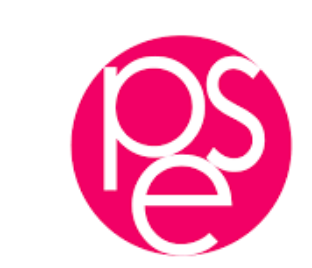

PARISSCHOOL OFECONOMICS
ECOLED'ECONOMIEDE PARIS

WORKING PAPER N 2019 - 68

Demographics in MENA countries:

a major driver for economic growth

\author{
Yeganeh Forouheshfar \\ Najat El Mekkaoui \\ Hippolyte d'Albis
}

JEL Codes: J11; E17; 016

Keywords: Financial efficiency; Development; MENA region; Demographic transition

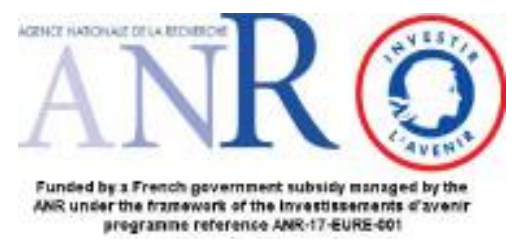




\title{
Demographics in MENA countries: a major driver for economic growth
}

\author{
Yeganeh Forouheshfar ${ }^{1} \quad$ Najat El Mekkaoui ${ }^{1}$ \\ Hippolyte d'Albis ${ }^{2 *}$ \\ ${ }^{1}$ Université Paris-Dauphine, PSL Research University, IRD, \\ LEDa,UMR 225, DIAL \\ 2 Paris School of Economics, CNRS
}

December 2019

${ }^{*}$ Corresponding author. E-mail address: hdalbis@psemail.eu 


\title{
Demographics in MENA countries: a major driver for economic growth
}

\begin{abstract}
MENA region is undergoing rapid demographic transition, where $50 \%$ of the population is under the age 25 and high youth unemployment rates are argued to be one of the main sources of political instability. Fighting youth exclusion from work is one of the main challenges in the region. In this paper we evaluate the economic impact of the demographic transition for selected countries which experience different speeds of transition, namely: Iran, Morocco and Egypt.

The impact of demographic shift on the evolution of human capital stock and physical capital stock, has been highlighted by the literature. Since financial markets play a crucial role to allocate capital and channel the funds to the productive sector, it is hence fundamental to take into account the role of the financial markets in the growth process associated with demographic change.

We have developed a general equilibrium overlapping generations model with a cost for capital mobilisation as a proxy for financial markets' efficiency. We have found that the demographic shift will be an important driver for growth in the upcoming decades. Furthermore, our results show that a more efficient financial sector leads to better economic performance. Specifically, youth are the primary beneficiaries: an increase in the financial sector efficiency can reduce up to 8 percentage points of the youngest age group unemployment.
\end{abstract}

JEL classification: J11; E17; O16

Keywords: Financial efficiency; Development; MENA region; Demographic transition

This research has benefited from financial support by PSL Research University, Programme d'Investissements d'avenir, ANR-10-IDEX-0001-02 PSL.

We thank all participants of the MCD seminar at International Monetary Fund, and specially Hossein Samiei for their helpful remarks and comments. Any errors remain ours. 


\section{Introduction}

Middle East and North African (MENA) countries are facing political and economical and challenges, requiring an urgent implementation of structural reforms to enhance inclusive growth. In spite of relatively high educational attainments, youth in the region are excluded from many economic opportunities. In fact, youth unemployment rates in the MENA region are among the highest in the world reaching $26.2 \%$ in 2018 (World Bank).

The demographic transition in the region started relatively late, compared to Latin America and Southeast Asia. However it is happening considerably faster and could be regarded as an opportunity. All the countries in the region are facing the same demographic transition and could benefit from the twin "demographic dividends". The first dividend arises from changes in the population's age structure that influence the share of the working age population (given fixed output per worker, participation and unemployment rates) this leads to an increase in output per capita. The second dividend comes from the increased capital due to the savings of a larger number of middle-aged workers approaching their retirement (see Mason (2005)).

In this paper, we highlight the demographic opportunity in the region through the selection of three countries, Iran, Morocco and Egypt, which face different speeds of demographic change. Iran fertility rate decline has been one of the fastest in the world, it took only a decade for the fertility rate to drop from more than 6 births per woman to less than 3, which is even faster than China's. In Morocco, this transition took 22 years. In Egypt, even though, the fall in fertility rates started earlier and the number of births per woman dropped under 6 by 1970, it took 47 years to only reach a rate of 3.3 as of 2017 (United Nations, Department of Economic and Social Affairs, Population Division (2019)). Hence, Iran, Morocco and Egypt have been chosen to represent fast, medium and slow demographic transition.

The labor market in MENA region is under high pressure with an unemployment rate of $10.6 \%$ in 2017: on the supply side, due to the demographic changes there is a massive entrance of youth to the labor market, while on the demand side, job creation happens at a very low pace. In MENA oil-importer countries, this is due to the large share of governmental jobs while MENA oil-exporting countries suffer from the dependance to the oil sector, which is not a labor intensive sector. Moreover, technological improvements lead to less labor intensive jobs. This leads to critically high unemployment rates in the region which reached $12.3 \%, 9.2 \%$ and $11.8 \%$ for Iran, Morocco and Egypt respectively (2018, World Bank).

Another specificity of the region, is that the labor force had the fastest annual growth rate in the world ( $2.7 \%$ in the past 10 years), at the same time this demo- 
graphic shift comes more as a demographic challenge since the youth unemployment in the region is also among the highest: in 2015, youth unemployment reached $30 \%$ in Iran and Morocco and is higher than $40 \%$ in Egypt. ${ }^{1}$

Therefore, the demographic change not only matters for the stock of human capital but also for the stock of physical capital. Financial markets have a crucial role to allocate capital and channel the available funds to their most productive use, it is hence fundamental to take into account the role of the financial markets in the growth process associated with demographic change. Even though financial markets in the region are still underdeveloped and are subject to change, improving their efficiency could potentially enhance economic growth.

Our aim is to evaluate the effect of a demographic shift on economic growth, to identify factors that can promote youth employment and to estimate whether a gain in the efficiency of the financial sector can stimulate youth employment. In the process of evaluating the effect of the demographic shift on growth, we develop a measure of financial market efficiency in the model, as a proxy for the cost of capital allocations. This cost represents the inefficiencies of the financial sector and can reflect the systemic inefficiencies such as corruption, poor management, poor loans within the banking system (which are majorly under reported) or a lack of skilled professionals in the financial sector. Additionally, it can represent the cost associated with restrictive regulation and taxation of financial transactions.

Our focus is on selected MENA countries, namely, Iran, Morocco and Egypt. Similar to most countries in the region, all of these countries face persistent high youth unemployment rates and their demographic transition is imminent. Hence, we expect a massive entrance of young workers in the labor market followed by a fall in the upcoming decades. Although the fall is happening at different rates, it will severely impact the economy.

Our contribution to the literature is firstly, to employ the cost of capital mobilization as a proxy for the financial sector efficiency in a general equilibrium Overlapping Generations Model. Which allows us to study the impact of demographic evolution and financial markets efficiency on growth in a single model. Secondly, we use real data of the demographic evolution per age group that assembles information regarding both fertility rates and mortality rates. However most researches, dealing with demography, focus on the evolution of the fertility or population growth rates, others such as Lagerlöf (2006) introduce endogenous fertility. All of which, does not include information on mortality rates among cohorts. Thirdly, the paper concentrates on Iran, Morocco and Egypt, three countries in MENA, a region of growing interest that is somehow neglected in the literature.

\footnotetext{
${ }^{1}$ Unemployment rate for ages between 12 to 24 , given by national statistics.
} 
This paper is organized as follows: after the literature review in section two, the model is introduced in the third section, the forth section details our calibration strategy, results are presented in the fifth section and the last section concludes.

\section{Literature review}

This paper is relevant to three different strands in the economic literature, firstly, the research on the impact of demography on economic growth, secondly, studies on the influence of demographic structure and finance and thirdly, the literature on finance-growth nexus.

The impact of demographic evolution on economic performance has long been debated in the literature. Bloom and Canning (2004) argue that since the early 1980s the dominant academic belief was that the population growth is rather neutral to economic growth. However, the emerging evidence indicates that since people's needs and contributions to the economy vary over their life cycle; population does indeed matter to growth, with age structure playing a central role. As noted by Bloom et al. (2003) and Lee and Mason (2007), an increase in the share of the working-age population can in particular produce a demographic dividend with respect to economic growth. Moreover, Chakraborty (2004), studies the impact of mortality rates on the economy, notably on savings and education decisions. Favero et al. (2011) and Favero et al. (2015), provide empirical evidence based on US data, that underlies the importance of including population's age structure in the macrofinance models. Liao (2011) highlights the importance of demographic transition as a driver for growth and show that more than one-third of Taiwan output growth during the past four decades can be attributed to demographic transition. Heijdra and Mierau (2011) show that ageing generally promotes economic growth due to a strong savings response. Boucekkine et al. (2002), evaluate the impact of an increase in life expectancy on growth and conclude that although higher survival probabilities lead to better schooling and later retirement, it does not necessarily lead to higher economic growth. D'Albis (2007), determines the impact of a demographic change on per capita capital and finds that this relationship is rather non-monotonic, in contrary to the classical OLG models that find a strictly decreasing relationship between capital accumulation and age structure.Bloom et al. (2017) put forward the high potential of the African countries to enjoy a demographic dividend. Martins et al. (2005) study the impact of ageing in OECD economies, and imply that the change in the population's age structure affects the supply side of the economy in capital markets, labor markets and also productivity; they conclude that demographic structure has a real impact on GDP growth rates. Moreover, they highlight 
the importance of financial markets structures in the process. Our results show a significant positive impact of the demographic transition on economic growth, which is in line with this literature. Our paper contribute to this literature by performing a numerical exercice on an OLG setting and simulating future demographic trends by taking into account mortality rates forecasts of different age groups; also we focus on countries that are least treated in the literature.

The literature dealing with financial markets and demography mainly investigates the effect of a demographic change on the demand side of financial asset, by focusing on ageing. A common framework used in this literature is Overlapping Generations (OLG) with production and capital accumulation, the introduction of adjustment cost allows capital to be priced endogenously. Geanakoplos et al. (2004) show that demographic changes could impact asset prices; Abel (2003) shows that baby booms will eventually lead to a meltdown in stock prices as the current baby boom generation retires. The link between the change in demography and financial asset prices is the life cycle hypothesis, which suggests young people (aged 20-39) are likely to be net borrowers. While the middle-aged (aged 40-64) are involved heavily in accumulation of net assets because they are at the peak of their earnings potential, and likely to be saving for retirement. A relative increase in the size of this group would lead to a high demand for financial assets, e.g. stocks and bonds, resulting in an increase in financial asset prices. Similar to this literature, we also employ an OLG framework but we introduce a capital allocation cost as a proxy for financial efficiency and study its impact on employment rates notably for the youth.

The literature on Finance-Growth nexus has been largely studied in recent decades. However, there are few researches dedicated to the development of financial markets in the MENA region. Ben Naceur and Ghazouani (2007) underline the relationship between financial development and economic growth for 11 MENA countries, using a dynamic panel model with $\mathrm{GMM}^{2}$ estimators, their empirical results reinforce the idea that there is no significant relationship between banking or stock market development and growth. They conclude that this lack of relationship must be linked to underdeveloped financial systems in the MENA region which hamper economic growth, and that these countries should improve the functioning of their financial system in order to protect their economies from the negative impact of a shaky financial market. Ben Naceur et al. (2008), also focus on the MENA region, specifically, the impact of the stock markets on growth; they find a negative impact of the stock markets in the short run that turns positive in the long run. Greenwood et al. (2013) use a costly state verification model, and stress the importance of financial intermediation for economic development and conclude that 29 percent of U.S. growth can

\footnotetext{
${ }^{2}$ Generalized method of moments
} 
be attributed to technological improvements in financial intermediation. Although the impact of financial market development on growth is well addressed in these studies, to our knowledge there is no literature on the impact of financial efficiency on economic growth that controls for demographic changes, our goal is to fill this gap in the literature.

\section{A dynamic general equilibrium model with a capital mobilisation cost}

We develop a general equilibrium OLG model and introduce the financial sector efficiency to the real sector, with search and matching structure in the labour market ła Diamond-Mortensen-Pissarides (DMP). Following Pagano (1993), we introduce an investment cost as a proxy for financial markets' efficiency. For the sake of simplicity we do not introduce retirement in the model, although this will be a shortcoming in the case of studying an ageing population. ${ }^{3}$

Our focus is on the individual's behaviour when they are active in the labor market, more specifically, agents between age 15 to 64 . Average schooling years in 2016 equals 9.8 for Iran, 5.4 for Morocco and 7.2 in Egypt (UNDP data). Hence we assume people approximately enter the labor market when they are 15 year old. Each period of time in the model stands for 10 years, individuals are assumed to enter the labor market at age 15-24 $(a=0)$ and leave it at age 55-64 $(a=4)$.

$Z_{a, t}$ represents the population of age $a$ in period $t$. The size of the initial cohort (population at age $a=0$ ) is known, i.e. $Z_{0, t}$ is known, let $\beta_{a, t}$ the conditional survival probability of reaching age $a$ in period $t$, if the agent have survived until age $a-1$ in period $t-1$. The total population of age $a$ in period $t$ is given by ${ }^{4}$ :

$$
Z_{a, t}=\beta_{a, t} Z_{a-1, t-1} \quad \forall t \geq 1
$$

We suppose that the participation rate is exogenous and normalized to 1 . and since the individuals stay in the labor force until their last period, the working age population is given by $Z_{t}$ :

$$
Z_{t}=\sum_{a=0}^{4} Z_{a, t}
$$

\footnotetext{
${ }^{3}$ The pension schemes are not very well developed in the region and many elderly stay in the labor market or depend on their children.

${ }^{4}$ Considering migration is beyond the scope of this paper.
} 
Agents of working age are either employed $\left(N_{a, t}\right)$ or unemployed $\left(U_{a, t}\right)$ with $n_{a, t}$ and $u_{a, t}$ representing the employment and unemployment rates:

$$
Z_{a, t}=N_{a, t}+U_{a, t}=\left(n_{a, t}+u_{a, t}\right) Z_{a, t}
$$

The labor market has a Diamond-Mortensen-Pissarides (DMP) search and matching structure, in which firms post vacancies at a cost and jobs are distributed through a basic search and matching model and wages are determined in each period by a Nash bargaining solution. ${ }^{5}$ We assume that there is a constant returns to scale matching function:

$$
M_{t}=M\left(V_{t}, \Omega_{t}\right)=\bar{m} V_{t}^{1-\gamma} \Omega_{t}^{\gamma}
$$

With $M_{t}$ denoting the number of possible matches between job seekers and the vacancies, $V_{t}$ the number of vacancies available and $\Omega_{t}$ the number of job seekers in period $t$. Let $\Omega_{a, t}$ represent the number of job seekers of age $a$ in period $t$, then, the total number of job seekers in each period, $\Omega_{t}$, is given by the sum of job seekers in all ages: $\Omega_{t}=\sum_{a=0}^{4} \Omega_{a, t}$ At age 0 every agent, entering the market is a job seeker, $\Omega_{0, t}=Z_{0, t}$

For ages above 0 the number of job seekers is given by the unemployed in the previous period plus those how have lost their jobs in the past period (with $\chi$ being the job destruction rate):

$$
\begin{aligned}
\Omega_{a, t} & =\left(u_{a-1, t-1}+\chi n_{a-1, t-1}\right) Z_{a, t} \\
& =\left(1+(\chi-1) n_{a-1, t-1}\right) Z_{a, t} \quad \text { for } \quad a=\{1,2,3,4\}
\end{aligned}
$$

Hence,

$$
\Omega_{t}=\sum_{a=0}^{4} \Omega_{a, t}=Z_{0, t}+\sum_{a=1}^{4}\left(1+(\chi-1) n_{a-1, t-1}\right) Z_{a, t}
$$

The probability of finding a job denoted by $p_{t}$, and the probability for a vacancy to be filled, $q_{t}$ are given by:

$$
p_{t}=\frac{M_{t}}{\Omega_{t}} \quad \text { and } \quad q_{t}=\frac{M_{t}}{V_{t}}
$$

\footnotetext{
${ }^{5}$ The classical contributions are given in Diamond (1981), Pissarides (1985) and Mortensen and Pissarides (1994).
} 
The employment rate for workers in age group $a$ is equal to non-destroyed jobs from the last period, plus new hires of this period:

$$
n_{a, t}=(1-\chi) n_{a-1, t-1}+p_{t} \frac{\Omega_{a, t}}{Z_{a, t}} \quad \text { for } \quad 1 \leq a \leq 4
$$

and

$$
n_{0, t}=p_{t}
$$

By replacing $\Omega_{a, t}=\left(1-(1-\chi) n_{a-1, t-1}\right) Z_{a, t}$ we obtain the law of motion for employment:

$$
n_{a, t}=(1-\chi) n_{a-1, t-1}\left(1-p_{t}\right)+p_{t} \quad \text { for } \quad 1 \leq a \leq 4
$$

We have a representative agent for each age category with perfect foresight, who does not leave intended bequest. All agents in the economy are price takers. The objective function of the households depends on their consumption and employment status, it is given by:

$$
W_{t}^{H}=\max \sum_{a=0}^{4}\left(\frac{1}{1+\theta}\right)^{a} \beta_{a, t+a}\left(u\left(c_{a, t+a}\right)-d_{n} n_{a, t+a}\right)
$$

Where $\theta>0$ is the time preference and $d_{n}$ is the constant disutility per unit of work and is supposed to be constant. We assume that there is no government in this model. This hypothesis is convenient, since the tax rates are relatively low in the countries of this study, and in general the government in these countries does not play an active role in providing citizens with good and widespread social security and pension schemes, therefore, we assume that the government's debt policy can not be used as a vehicle for redistributing of wealth among generations.

The household budget constraint at time $t+a$ is given by:

$$
\left(w_{a, t+a} n_{a, t+a}\right)+\frac{\beta_{a-1, t+a-1}}{\beta_{a, t+a}}\left(1+r_{t+a}\right) s_{a-1, t+a-1}=c_{a, t+a}+s_{a, t+a}
$$

With $s_{a, t}$ be the financial wealth accumulation at time $t$ in per capita terms or simply the savings rate. The financial wealth is either held in shares or physical capital. Following Yaari (1965), we suppose that there is perfect insurance against individual lifetime uncertainty, therefore the total return to savings is equal to gross risk free interest rate divided by the survival probability from period $t+a-1$ to the next period. 
Thus, the Euler equation for the households writes:

$$
u^{\prime}\left(c_{a, t+a}\right)=\frac{u^{\prime}\left(c_{a+1, t+a+1}\right)}{1+\theta}\left(1+r_{t+a+1}\right)
$$

For later use we need to calculate the value of an additional job for the household:

$$
\frac{\partial W_{t}^{H}}{\partial N_{a, t}}=\frac{Z_{0, t}}{Z_{a, t}} \sum_{j=0}^{4-a}\left(\frac{1}{1+\theta}\right)^{a+j}\left(\beta_{a+j, t+j}\right)\left(u^{\prime}\left(c_{a+j, t+j}\right) w_{a+j, t+j}-d_{n}\right) \frac{\partial n_{a+j, t+j}}{\partial n_{a, t}}
$$

with

$$
\frac{\partial n_{a+j, t+j}}{\partial n_{a, t}}=(1-\chi)\left(1-p_{t+1} \frac{\beta_{a, t}}{\beta_{a+1, t+1}}\right)\left(\frac{\partial n_{a+j-1, t+j-1}}{\partial n_{a, t}}\right)
$$

In this model we have a single production sector, which is assumed to behave competitively. Production is constant returns to scale, with two factors of production, namely, capital and labor. Labor is measured in efficiency units, $h_{t}$, and efficiency can vary across ages due to experience and also across generations due to education difference. The total labor input is defined as:

$$
H_{t}=\sum_{a=0}^{4} h_{a, t} N_{a, t}
$$

Production function of the representative firm is assumed to be a constant returns to scale Cobb-Douglas.

$$
Y_{t}=A_{t} F\left(K_{t}, H_{t}\right)
$$

Where $Y_{t}$ is the output produced in period $t$ and $A_{t}$ is the total factor productivity and $K_{t}$ is the capital stock.

Firms rent capital at cost $\nu_{t}$, which is an increasing function of the interest rate, depreciation rate of capital and the financial cost of capital, which we will define in the following section. In our model we focus on one of the main functions of the financial sector which is, mobilize savings.

With $\zeta$ being the cost of posting a vacancy. The firm will maximize the following Bellman equation:

$$
W_{t}^{F}=\max _{K_{t}, V_{t}}\left\{F\left(K_{t}, H_{t}\right)-\nu_{t} K_{t}-\sum_{a=0}^{4} w_{a, t} N_{a, t}-\zeta V_{t}+R_{t+1}^{-1} W_{t+1}^{F}\right\}
$$

Subject to: 


$$
\begin{gathered}
N_{a, t}=Z_{a, t} n_{a, t} \\
n_{a, t}=(1-\chi) n_{a-1, t-1}+p_{t} \frac{\Omega_{a, t}}{Z_{a, t}} \quad \text { with } \quad n_{0, t-a}=p_{t-a} \\
p_{t}=q_{t} \frac{V_{t}}{\Omega_{t}}
\end{gathered}
$$

Hence, we obtain the first order conditions:

$$
\begin{gathered}
\nu_{t}=F_{K_{t}} \\
\zeta=q_{t} \sum_{a=0}^{4} \frac{\Omega_{a, t}}{\Omega_{t}} \frac{\partial W_{t}^{F}}{\partial N_{a, t}}
\end{gathered}
$$

Note that $\zeta$ is the marginal cost of hiring and $\frac{\partial W_{t}^{F}}{\partial N_{a, t}}$ is the value at time $t$ of an additional worker of age $\zeta$ and is given by:

$$
\begin{aligned}
\frac{\partial W_{t}^{F}}{\partial N_{a, t}} & =\frac{1}{Z_{a, t}} \frac{\partial W_{t}^{F}}{\partial n_{a, t}} \\
& =\sum_{j=0}^{4-a} \frac{\beta_{a+j, t+j}}{\beta_{a, t}} \frac{(1-\chi)^{j}}{1+r_{t+j}}\left(h_{a+j, t+j} F_{H_{t+j}}-w_{a+j, t+j}\right)
\end{aligned}
$$

This condition shows that, in the equilibrium the marginal cost of hiring should be equal to the marginal value of employment to the firm.

Wages are negotiated in every period and are determined by a standard Nash bargaining rule:

$$
\max _{w_{a, t}}\left(\frac{\partial W_{t}^{F}}{\partial N_{a, t}}\right)^{1-\eta}\left(\frac{1}{u_{c_{a, t}}^{\prime}} \frac{\partial W_{t}^{H}}{\partial N_{a, t}}\right)^{\eta}
$$

The first order optimality condition is given by:

$$
(1-\eta) \frac{1}{u_{c_{a, t}}^{\prime}} \frac{\partial W_{t}^{H}}{\partial N_{a, t}}=\eta \frac{\partial W_{t}^{F}}{\partial N_{a, t}}
$$

All agents in this economy are price-takers and all markets are competitive. There are 3 markets in our economy: market for capital, labor and a physical good which is either consumed or invested to built future capital. The equilibrium conditions are: 
- Labor market equilibrium: the equilibrium is given by the wages and the Nash bargaining solution in equation (26).

- Good market equilibrium: we have the good market equilibrium as:

$$
\sum_{a} c_{a, t} Z_{a, t}+I_{t}=Y_{t}
$$

- Capital market equilibrium and the investment cost: The capital market equilibrium, in the absence of government and perfect financial markets calls for the aggregate gross saving, $S_{t}=\sum_{a} s_{a, t} Z_{a, t}$, to be equal to the gross investment, $I_{t}$. Here, following Pagano (1993) and as explained later, we assume that a proportion, $1-\varphi$ of the savings is 'lost' in the process of financial intermediation, so the equilibrium condition writes:

$$
\varphi S_{t}=I_{t}
$$

Where $\varphi$ indicates the presence of financial market friction and represents the amount of investment produced by one unit of savings. This can reflect the $\mathrm{X}$-inefficiency of the intermediaries, that is a a non-allocative inefficiency with unknown origins that makes the final outcome deviating from the optimal outcome (see the seminal work of Leibenstein (1966)). This 'lost' share of savings may also represent what is absorbed by the financial intermediaries, for instance as the spread between lending and borrowing rates that goes to banks or fees charged by the financial intermediaries. It may also reflect the systemic inefficiencies such as corruption, poor management, poor loans within the banking system who are majorly under reported or lack of skilled professionals in the financial sector. Additionally, it can represent the cost associated with restrictive regulation and taxation of financial transactions. According to this definition $0<\varphi \leq 1$ with $\varphi=1$ representing perfect financial markets.

Thus, we model the efficiency of the financial sector as a change in financial transaction cost. Households save the amount $S_{t}$ and receive in the next period $\left(1+r_{t+1}\right) S_{t}$. Firms on the other hand, only receive a fraction of these savings due to the presence of transaction costs, $\varphi_{t} S_{t}$, with $0<\varphi \leq 1$, and $(1-\varphi)$ What will remain from the initial savings after the production process, is the depreciated investment which would be equal to $(1-\delta) \varphi_{t} S_{t}$, hence, the total cost of capital for the firm in the period $t+1$, writes:

$$
\nu_{t+1} \varphi S_{t}=\left(1+r_{t+1}\right) S_{t}-(1-\delta) \varphi S_{t}
$$




$$
\begin{gathered}
\nu_{t+1}=\frac{1+r_{t+1}}{\varphi}-(1-\delta) \\
r_{t}=\varphi\left(1-\delta+\nu_{t}\right)-1
\end{gathered}
$$

Equation (31) shows that an increase in the financial sector efficiency, translated to an increase in $\varphi$, which will lead to, ceteris paribus, an increase in the interest rates. We need to distinguish this definition of cost of capital from the literature on adjustment cost for investment, since the nature of these two are completely different and the cost of capital that we have defined is due to financial markets transaction costs and independent of the production process or the nature of the investment.

We can define $R_{t}\left(\varphi, r_{t}\right) \equiv \frac{1+r_{t}-\varphi}{\varphi}$ to finally obtain the cost for capital, similar to the canonical model:

$$
\nu_{t}=R_{t}\left(\varphi, r_{t}\right)+\delta
$$

We can interpret $R_{t}\left(\varphi, r_{t}\right)$ as the interest firms pay for their capital which is not the same interest that households receive $r_{t}$ due to financial market fees $\left(R_{t}\left(\varphi, r_{t}\right)>r_{t}\right)$.

The stock of the capital in the next period is constructed by investment in the current period plus the depreciated capital of the previous period, hence the capital accumulation equation writes:

$$
K_{t+1}=I_{t}+(1-\delta) K_{t}
$$

\section{Calibration}

The focus of this paper is on selected MENA countries, namely, Iran, Morocco and Egypt. This selection is due to different demographic characteristics, notably the speed of decline in the fertility rate. The parameters of the model are set to reflect the economic situation, labor market tensions and the demographic shifts in these countries.

\section{Parameters}

The main parameters remain the same across the selected countries, the major difference is in demographics which is detailed in the following section. There are four different categories of parameters in the model: 
General technological and preference parameters; these parameters are mostly uncontroversial and are set to values consistent with previous contributions or microeconomic evidence. A constant returns to scale Cobb-Douglas production function, with elasticity of output with respect to capital set at $\alpha=0.33$. Total factor productivity is set to produces the same gap in GDP per capita among the countries as we observe in the data. ${ }^{6}$ Other technological and preference parameters are reported in Table 1.

The second category of parameters, is the age dependent productivity of agents. Skirbekk (2004) gives a survey of the literature regarding the productivity of the labor force for different age groups. Most studies show a considerable decline in productivity after age 50, as a result of the decline in cognitive and mental abilities, which is considered a universal phenomenon. ${ }^{7}$ According to Sibai et al. (2014) older people in the region suffer from chronic diseases which contributes to lower their productivity. Our main assumption here is that the age-productivity profile remains the same among the countries of our study and as suggested by empirical findings, increases until the age of 50, and then decreases very slowly. This is similar to Heijdra and Reijnders (2016), who take into account both human and physical capital accumulation in their model. They assume that the labour market participation leads to a higher human capital stock as valuable experience is gained; this human capital stock diminishes with ageing and finally prompt the individuals to exit the labor force. Hence the age specific human capital is calculated to form an inverse U-shaped curve and to reflect the wage differentials among age groups, their values are reported in Table $1 .{ }^{8}$

The third category, gathers labor market parameters. These parameters are associated with a frictional labor market. The matching process is a constant returns to scale Cobb-Douglas function, the elasticity of matches with respect to vacancies, $\gamma$, and the workers' bargaining power, $\eta$, are set at 0.5 The matching efficiency parameter, $\bar{m}$, and vacancy cost, $\zeta$, are set to target the final steady state of finding job and posting a vacancy at $90 \%$, since according to national statistics the unem-

\footnotetext{
${ }^{6} \mathrm{TFP}$ is set to 21, 18.9 and 19.5 in Iran, Morocco and Egypt respectively.

${ }^{7}$ Age-productivity profile is estimated almost always by wage differentials, which is quite debatable as the rewards to the seniors maybe due to loyalty or past achievements rather than current productivity, on the other hand older workers importance to the companies is difficult to measure since it can be due to wider networks, knowing better how to deal with problems with lower frequencies etc. Hence, although wage differentials are not the ideal measures for productivity, they are considered one of the best so far.

${ }^{8}$ In order to verify that our results are not simply a response to the calibration of the human capital we perform a robustness check in Appendix C, where, we set the human capital contant among different age groups.
} 
ployment rate is around $10 \%$ in the countries in our sample ${ }^{9}$. The job destruction rate is calculated based on the KILM data set by $\mathrm{ILO}^{10}$, it is estimated by quarterly unemployment inflows and is around 0.004 for the countries in MENA region. Table 1 , brings together all these parameters.

Table 1: Calibration details

\begin{tabular}{|c|c|c|c|}
\hline$\overline{\overline{\text { Symbol }}}$ & Definition & Value & Source \\
\hline \multicolumn{4}{|c|}{ General technological and preference parameters } \\
\hline $\bar{\alpha}$ & Elasticity of output with respect to capital & 0.33 & Börsch-Supan et al. (2006) \\
\hline$\theta$ & Time preference (quarterly) & 0.01 & Hagedorn and Manovskii (2008) \\
\hline$\delta$ & Depreciation rate of capital & $5 \%$ annually & Börsch-Supan et al. (2006) \\
\hline$d^{n}$ & Disutility of working & 0.25 & de la Croix et al. (2013) \\
\hline \multicolumn{4}{|c|}{ Age specific human capital } \\
\hline$\overline{h_{0}}$ & Human capital for agents of ages within 15-24 & 1.3647 & Authors' calculation \\
\hline$h_{1}$ & Human capital for agents of ages within $25-34$ & 2.3647 & Authors' calculation \\
\hline$h_{2}$ & Human capital for agents of ages within $35-44$ & 4.3647 & Authors' calculation \\
\hline$h_{3}$ & Human capital for agents of ages within $45-54$ & 6.8647 & Authors' calculation \\
\hline$h_{4}$ & Human capital for agents of ages within $55-64$ & 6.3647 & Authors' calculation \\
\hline \multicolumn{4}{|c|}{ Frictional labor market parameters } \\
\hline $\bar{\gamma}$ & Elasticity of matches with respect to vacancies & 0.5 & de la Croix et al. (2013) \\
\hline $\bar{m}$ & Matching efficiency parameter & 0.9 & Targeting $p$ and $q=0.9$ \\
\hline$\eta$ & Bargaining power of workers & 0.5 & de la Croix et al. (2013) \\
\hline$\chi$ & Job destruction rate (quarterly ) & 0.004 & ILO, KILM 9 dataset \\
\hline$\zeta$ & Cost of posting a vacancy & 43.5 & Targeting $p$ and $q=0.9$ \\
\hline
\end{tabular}

The forth category of parameters are specific to the financial sector development. According to Lesmond et al. (1999), estimated transaction costs vary from $10 \%$ for small firms to $1 \%$ for large firms in developed economies. Naturally this figure is much higher in MENA region which has a less developed financial sector. We assume that the cost of allocating capital is $20 \%$, when the financial markets are relatively inefficient. This cost can be reduced in the case of financial market efficiency improvement, meaning that the variable $\varphi=0.8$ when financial markets are inefficient and it can reach $\varphi=1$ where financial markets are so efficient that the cost of capital allocations falls close to 0 . We also perform a robustness check with the transaction cost of $10 \%$, and end up with similar results to those reported in Appendix B.

\section{The demographic shift}

\footnotetext{
${ }^{9} 10.2 \%$ for Morocco, $13 \%$ for Egypt and $12.8 \%$ for Iran in 2014 .

${ }^{10}$ In Key Indicators of the Labour Market (KILM) dataset, we have the job destruction rate for Morocco, for Iran and Egypt its value is supposed to be similar.
} 
According to Equation (1) the parameters that define the population dynamics in the model are $Z_{0, t}$ and $\beta_{a, t}$, which are the size of the initial cohort and the probability of reaching age $a$ in period $t$ if the agent has already survived to age $a-1$ in period $t-1$, respectively. These parameters are set to replicate the World Population Prospects data set by UN. ${ }^{11}$ The use of real data on population allows us to incorporate information about mortality rates by age in our analysis, which is one of the distinctive features of this paper since most of the literature simulate demographic shocks solely by considering the evolution of the fertility rates. The values of $Z_{0, t}$ and $\beta_{a, t}$ in each period are reported in Appendix A along side of the dynamics of population evolution per age group as well as the total population and its growth rate for each country.

We consider the period where the share of the youngest age group surpasses the share of the oldest age group in the working age population as a turning point in the demographic shift of each country. Thus, according to Figure 1 the turning points for Iran, Morocco and Egypt are 2040, 2070 and 2100 respectively. This also reflects the speed of the demographic shift and the aging process in the labor force which is the fastest for Iran and the slowest for Egypt.

\section{Financial efficiency shock}

In order to study the impact of financial efficiency improvement on the economy ${ }^{12}$, we consider different scenarios for the improvement of the financial sector efficiency. In the "Baseline scenario" the cost for allocating capital remains unchanged and the evolution of variables are solely a response to the change in the demographic structure. The "High scenario", in addition to the demographic change, consists of a $50 \%$ decline in the cost of capital allocation in every period or every decade; and the "Low scenario", is a very gradual improvement in the sector corresponding to $5 \%$ decline in the cost for mobilizing capital. In both of these scenarios the decrease in the capital's cost start in 2010, Table 2 represents the value of $(1-\varphi)$ in each period under each scenario.

In other words, our "Baseline scenario" takes into account only the demographic changes, while "High scenario" studies the impact of a continuous huge and significant reform in the financial sector on these demographic changes and "Low scenario"

\footnotetext{
${ }^{11}$ United Nations, Department of Economic and Social Affairs, Population Division (2015). World Population Prospects: The 2015 Revision, custom data acquired via website.

${ }^{12}$ The main focus of this paper is on the efficiency of the financial sector and not its size. Some studies such as Arcand et al. (2015) show that if the financial sector grows too large it would harm the real economy. Our main assumption here is that the financial sector gets more efficient over time but identifying the reforms in the sector that go hand in hand with capital allocation efficiency is beyond the scope of this paper.
} 
Table 2: The value of $(1-\varphi)$ or the cost of capital accumulation under different scenarios

\begin{tabular}{lrrrrrrrrrr}
\hline \hline Period & 1 & 2 & 3 & 4 & 5 & 6 & 7 & 8 & 9 & 10 \\
\hline Baseline & 0.2 & 0.2 & 0.2 & 0.2 & 0.2 & 0.2 & 0.2 & 0.2 & 0.2 & 0.2 \\
High & 0.2 & 0.1 & 0.05 & 0.025 & 0.0125 & 0.0062 & 0.0031 & 0.00156 & 0.00078 & 0.00039 \\
Low & 0.2 & 0.19 & 0.18 & 0.17 & 0.16 & 0.15 & 0.147 & 0.139 & 0.132 & 0.126 \\
\hline \hline
\end{tabular}

focuses on small but continuous reforms in the financial sector. 
Figure 1: The evolution of the share of the youngest and oldest age group in the labor force
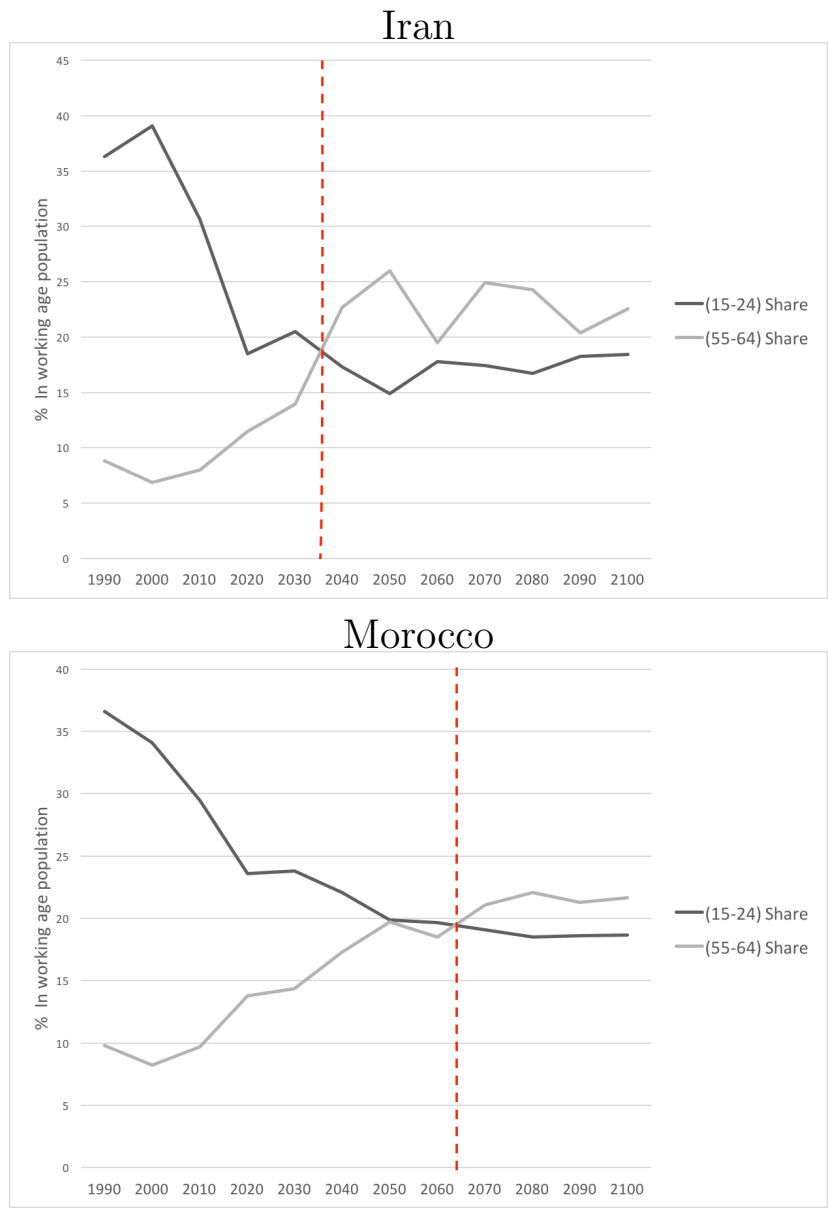

Egypt

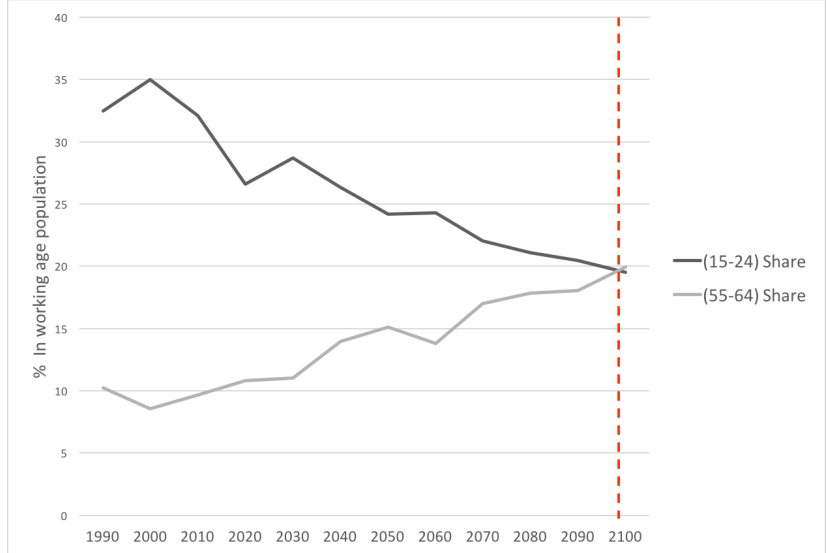




\section{Results}

We start by presenting the results of the impact of a demographic shift on GDP growth, employment rate, savings, wages and interest rate. Then we compare the dynamics of each indicator under different scenarios for financial efficiency improvement.

\section{Growth}

In order to quantify the effect of the labor force ageing on growth, and to exclude the effect of the population size, it is useful to look at the GDP per capita's evolution (see Figure 2). GDP per capita rises as the population ages, it tends to stabilise at the turning point of the demographic shift, i.e. for Iran in 2040 and for Morocco in 2070, in the same time for Egypt it continues to rise until the last period, i.e. 2100. Our findings are in line with D'Albis (2007) and Boucekkine et al. (2002), who find a non-monotonic impact of the demographic evolution on the economy. The main difference of our work is that unlike D'Albis (2007) who only takes into account the evolution of the physical capital and Boucekkine et al. (2002) who focus only on the human capital, we consider the evolution of both physical and human capital. Secondly, those papers study the impact of an increase in population's growth rate (as a response to fertility shocks), while our paper uses real data on population structure, which also includes information about mortality rates that may have a different effect on GDP per capita.

One can also note that the rise in GDP per capita is higher under the High scenario, showing the positive impact of the financial sector efficiency improvement on GDP per capita. Table 3 reports the percentage rise in GDP per capita in the last period of the simulations, compared to its initial level in 2000. Morocco benefits the most from a gain in the efficiency of the financial sector and ends up with 26.37 percentage point higher GDP per capita under the High scenario. We expect this gain in GDP per capita to lead to a significant fall in unemployment rates.

Table 3: GDP per capita in 2100

\begin{tabular}{lccccc}
\hline \hline & Baseline & High Scenario & Low Scenario & $\begin{array}{c}\text { P.P. difference between } \\
\text { High and the baseline }\end{array}$ & $\begin{array}{c}\text { P.P. difference between } \\
\text { Low and the baseline }\end{array}$ \\
\hline Iran & 69.63 & 92.65 & 76.93 & 23.02 & 7.3 \\
Morocco & 61.84 & 88.21 & 72.66 & 26.37 & 10.82 \\
Egypt & 43.78 & 68.73 & 53.38 & 24.95 & 9.6 \\
\hline \hline
\end{tabular}

Note: The numbers are represented as the percentage difference from the initial value of GDP per capita in 2000. For instance, under the baseline scenario, the GDP per capita in Iran in 2100 is $69.63 \%$ higher than its value in 2000 . 
Employment

The OLG framework makes it possible to distinguish between different age groups, the unemployment rates vary significantly among ages, with the youth having the highest unemployment rate of around $40 \%$ while the unemployment rate for the oldest agents is a quarter of it. These figures are in line with the data from the labor market in the region and highlights the fact that most of the tension in the labor market is on youth.

The demographic evolution can affect unemployment via two direct channels. Firstly, through an increase in population and the labor force that may lead to higher unemployment by the supply-demand mechanism. Secondly, through the change in the age structure of the population; as the population ages, the unemployment rate falls. The main reason is that the unemployment rate is higher among the youth, because individuals are more experienced at older ages, hence more productive and subject to higher human capital; besides, they were present in labor market over a longer period of time, hence they have a higher probability to be employed. Furthermore, there is an indirect channel at play, which is through physical capital accumulation. As the population ages, the aggregate savings increase because older age groups tend to save more, which leads to a higher investment and job creation, hence, lower unemployment rates.

Table 4 reports the unemployment rates in the first and the last period of the simulation under the Baseline and High scenario for all age groups, as well as, the total unemployment rate. It shows that the demographic evolution has a powerful negative impact on unemployment rates. The demographic transition alone is responsible for $16,14.2$ and 10.3 percentage point decrease in the total unemployment rate in Iran, Morocco and Egypt, respectively. One can note that as the size of the youngest cohort is shrinking, the fall in the unemployment rate is the greatest for the younger cohorts.

Financial market efficiency improvement leads to greater stock of capital and consequently higher productivity of capital, thus, lower unemployment rates; and since the impact of the shock is clearly stronger under the high scenario, the unemployment rates are the lowest in this scenario. Younger age groups benefit more from the efficiency gain in the financial sector; while the gain can be as high as $8.3 \mathrm{pp}$ for the youngest cohort, it does not surpass $2.5 \mathrm{pp}$ for the oldest one.

One can also note that the drop in the unemployment rate is sharper for Iran, who faces a more abrupt fall in its fertility rates (higher demographic dividend), than Morocco, where the fertility rates decline at a smoother pace. The fall in unemployment rates is the lowest for Egypt, where fertility rates are rather stable and the demographic dividend is the lowest. 
Table 4: Unemployment rates in 2100

\begin{tabular}{cccccc}
\hline \hline & $\begin{array}{c}\text { Baseline } \\
(2000)\end{array}$ & $\begin{array}{c}\text { Baseline } \\
(2100)\end{array}$ & $\begin{array}{c}\text { High } \\
(2100)\end{array}$ & $\begin{array}{c}\text { Difference } \\
\text { Baseline-High } \\
(2100)\end{array}$ & $\begin{array}{c}\text { Difference } \\
\text { Baseline } \\
(2100-2000)\end{array}$ \\
Iran & & & & & \\
\hline $15-24$ & 40.5 & 22.3 & 15.7 & 6.6 & 18.2 \\
$25-34$ & 19.3 & 8 & 4.7 & 3.3 & 11.3 \\
$35-44$ & 12.6 & 5.2 & 3.2 & 2 & 7.4 \\
$45-54$ & 10.5 & 4.8 & 3.1 & 1.7 & 5.7 \\
$55-64$ & 9.9 & 4.7 & 3 & 1.7 & 5.2 \\
Total & 24.7 & 8.7 & 5.7 & 3 & 16 \\
\hline & & & & & \\
Morocco & & & & & 12.7 \\
\hline $15-24$ & 46.3 & 33.6 & 28.2 & 5.4 & 7.7 \\
$25-34$ & 25.7 & 14.7 & 11 & 3.7 & 7.9 \\
$35-44$ & 17.5 & 9.6 & 7.2 & 2.4 & 5.7 \\
$45-54$ & 14 & 8.3 & 6.3 & 2 & 14.2 \\
$55-64$ & 12.9 & 7.9 & 6.2 & 1.7 & \\
Total & 28.6 & 14.4 & 11.4 & 3 & 8.1 \\
\hline & & & & & 6.6 \\
Egypt & & & & & 4.7 \\
\hline $15-24$ & 42.7 & 34.6 & 26.3 & 8.3 & 3.5 \\
$25-34$ & 21.8 & 15.2 & 10.1 & 5.1 & 10.3 \\
$35-44$ & 14.7 & 10 & 6.7 & 3.3 & 2.7 \\
$45-54$ & 12.1 & 8.6 & 5.9 & 2.5 & \\
$55-64$ & 11.2 & 8.2 & 5.7 & 2.5 & \\
Total & 25.5 & 15.2 & 10.9 & 4.3 & \\
\hline \hline
\end{tabular}

Note: Unemployment rates in percentage in the Baseline and High scenario and their difference in percentage point. The last column represents the gain in employment rates as a response to demographic transition solely.

\section{Savings}

Savings is one of the most studied macroeconomic aggregates which has important implications on growth and consumption levels and its evolution is a determining factor for the dynamics of the OLG models. In fact, the importance of household's decision on savings in the model is twofold, it is an essential factor for wealth determination in the budget constraint, it also shapes the dynamics of the capital 
accumulation in the economy.

The dynamics of the unemployment and saving level are closely interrelated, higher levels of aggregate savings lead to abundance of physical capital, which in every neoclassical settings causes a fall in unemployment rate.

Figure 3 demonstrates the savings evolution per capita for different age groups. ${ }^{13}$ The savings is increasing during the agents lifecycle, here, since we do not have retirement in the model, we do not obtain a fall in the savings at the end of the lifecycle. Hence our results are consistent with the existing literature regarding the lifecycle model of savings. The demographic transition to an older labor force, globally makes the saving per capita increase for the youngest age group and decrease for the older ones who hold much higher savings, hence the saving per capita on average declines. This result is in line with the existing literature, as studied in detail by Heijdra and Ligthart (2006) who show that the per capita savings mostly decreases as a response to a fertility shock, although in theory it may increase if the effect of generational turnover is sufficiently strong to dominate the aggregate labor supply effect, this case is not empirically relevant.

\footnotetext{
${ }^{13}$ In this model, like any other overlapping generation settings with perfect foresight the savings is 0 for the oldest age group.
} 
Figure 2: GDP per capita evolution (percentage deviation from the initial steady state)
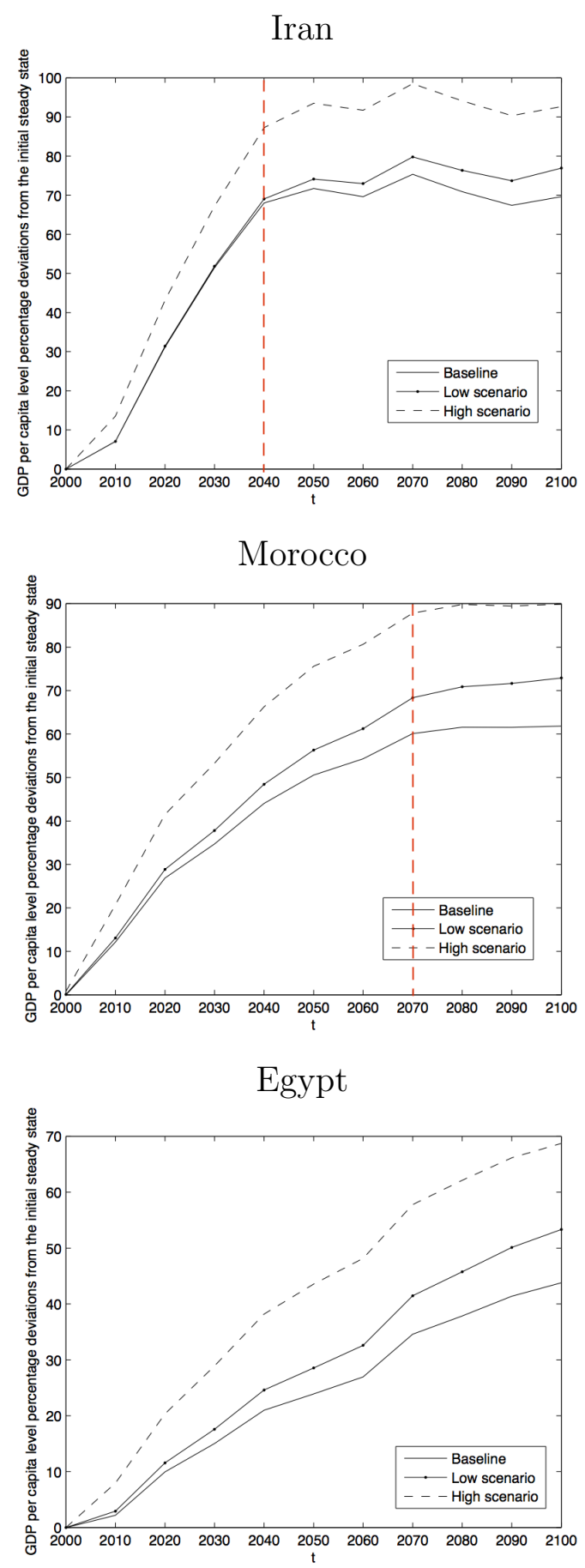
Figure 3: Savings per capita evolution by age

Iran
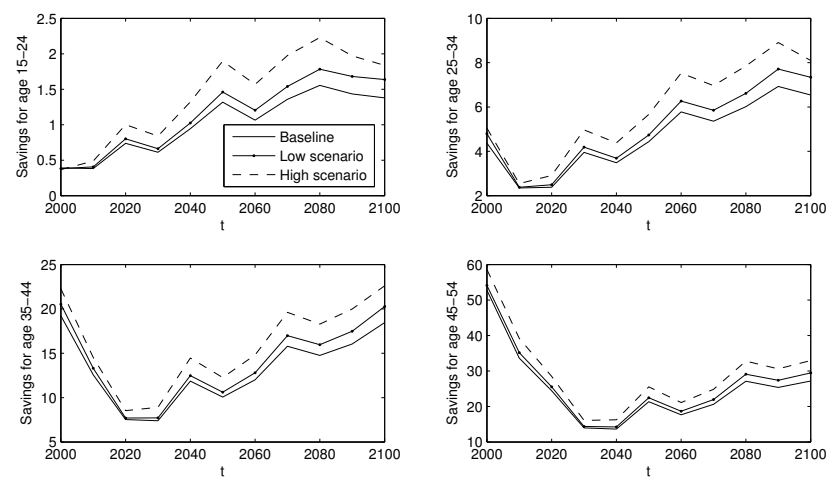

Morocco
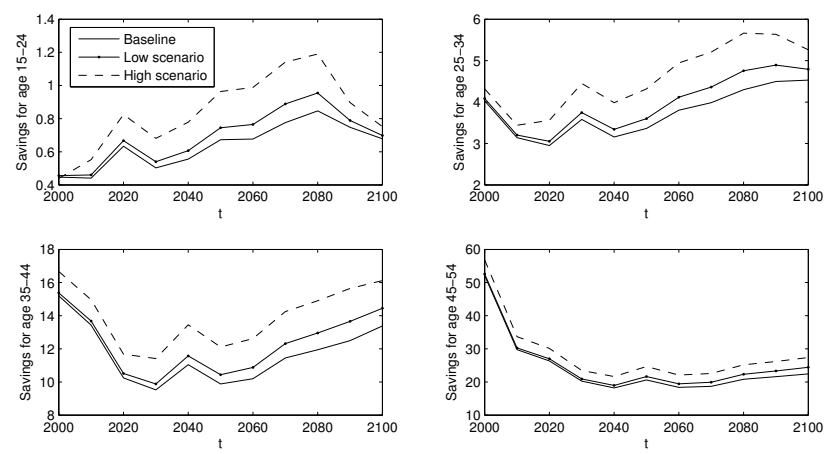

Egypt
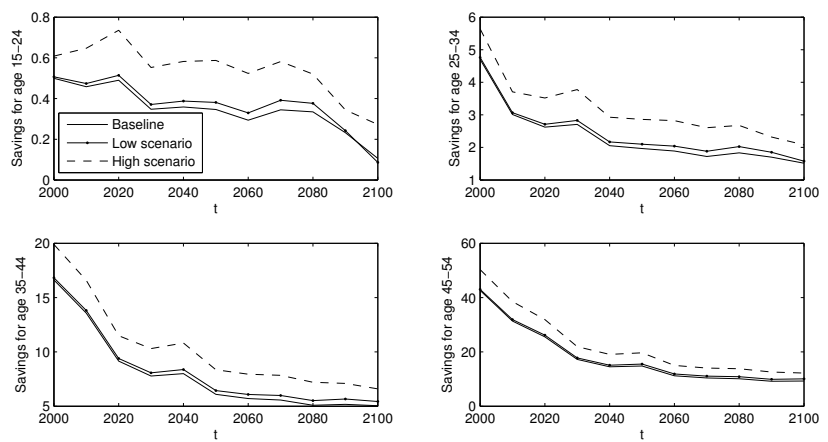

Note: Savings per capita for different age groups. According to the model's assumptions, the savings is null for the oldest age group (of age 55 to 64 ). Agents have perfect foresight and anticipate the upcoming shock in their savings decision that is the main reason the staring point in different scenarios may not be the same. 


\section{Discussion}

This study is focused on Iran, Morocco and Egypt. Although the demographic trends by age groups is at the center of our analysis and is taken into account in the model, one cannot neglect the uniqueness of the labor market structure of each country. Some key differences derive from the educational systems, with an overextended education in Iran and Egypt where average years of total schooling among the population of age over 25 in 2010 is 8.17 and 6.55 while the same figure for Morocco is 4.25 (Barro and Lee (2013)). In Iran 15.8 percent of the population of age 25 and above complete a tertiary education cycle, while in Egypt and Morocco this proportion is 6.8 and 6.3 respectively. This high educational attainment is not a guarantee to get a job and youth unemployment rates remain high, reaching 28.35, 21.88 and 32.59 in 2018, Iran, Morocco and Egypt respectively; causing the youth to be economically and politically excluded (World Bank). Moreover each country face their unique challenges that have implications on growth but remain out of the scope of this study, such as corruption and sanctions in Iran. Addressing these issues in a formal setting adds to the complexity of the model and should be treated in future research.

Our results demonstrate significant benefits of the demographic shift on economic activity. Governments can play an active role helping those potential benefits take place and preparing the youth to be absorbed in the labor market by investing in labor intensive jobs and developing training programs.

While the financial sector is undergoing various reforms, studying the potential impact of such reforms under the present demographic trends on the real economy is essential to nourish public debate and to ensure the application of the best relevant policies. Our results reflect the significant positive impact of financial sector efficiency gain, which means that the policy makers need to address efficiency of financial sector by taking different measures such as introducing competition in the financial sector, improving governance to boost productive investment, and by implementing an effective regulation to protect investors and bring certainty to the markets in the region. These policies should be accompanied with measures to enhance financial inclusion, as the financial exclusion notably for the youth and rural areas is a critical issue in the region (see Demirguc-Kunt et al. (2018)).

In order to keep our model computable and simple enough we had to make several strong assumptions, it is interesting to see what happens if these assumptions are relaxed or whether the data supports these assumptions:

- Absence of migration: Migration rates are negative for the countries of this study. This rate is the highest for Morocco with a significant human capital 
flight (with -7.22 migrants per 1000 population in 2017 compared to 3.4 in Iran and 1.9 in Egypt, Word Bank). For the sake of simplicity, agents do not have a choice to migrate or not in the model, hence migration is exogenous and is implicitly taken into account in the calculation of the mortality rates since the model is calibrated in way to reproduce the same population per age group as the UN data forecasts.

- Participation rates are constant and exogenous. This assumption is consistent with the data since the participation rates are quite stable over time and fluctuate between 40 to 50\% since 1970 to 2018 (World Bank). Although women participation rates are considerably lower and should normally rise as fertility drops and women get more educated, the participation rates stagnate. Assaad et al. (2018) refer to this as MENA Paradox.

- Absence of the government providing education: The growth model in this study take into account the exogenous component of growth which is physical capital. One interesting extension of the model to an endogenous growth model by including education and its intergenerational externalities.

- The productive sector behaves competitively: In order to focus on the inefficiencies of the financial markets and the labor market we have assumed that the firms behave competitively and the annuity markets are perfect. It would be very hard to interpret results if we have imperfections in all four markets.

\section{Conclusion}

In the MENA region, the demographic transition came relatively late but rather quickly, with a very sharp decline in fertility rates, leading MENA to be one of the youngest regions in the world. Youth represent a major driver for economic growth, they are the key to a strong economic development. This paper studies the impact of this demographic changes and the impact of a gain in the efficiency of the financial markets on economic growth in Iran, Morocco and Egypt.

We use a dynamic general equilibrium framework with overlapping generations and highlight that lower costs for investment lead to lower unemployment rates and higher output. The use of the OLG framework is due to the significant differences in unemployment rates for youth and old in the selected countries and more generally in the region, which is discussed to be one of the main sources of political tensions in the region. Our results show that the age structure of the labor force is a key 
component for employment and production dynamics and a more efficient financial sector will reduce the gap among younger and older age groups to some extent.

The novelty of this paper is to extend the theoretical relationship between demographic change and financial efficiency, and to focus on Iran, Morocco and Egypt, each country facing the demographic transition at a different pace. To our knowledge there is no similar model. Moreover, we take into account the evolution of both physical capital and labor market age structure. Furthermore, this paper uses real data on population structure, which not only considers fertility rates, but also information about mortality rates that may have a different effect on GDP per capita. As a matter of fact, our simulation results should be taken into account ceteris paribus, we focus on countries that are facing various major internal and external shocks that can result in different outcomes for unemployment and growth from the one which is estimated in the paper.

Globally the demographic forces lead to a significant decline in the unemployment rates for all age groups. Furthermore, the effect of a demographic shift on unemployment and GDP is mainly influenced by the dynamics of the share of youth in the working age population. GDP per capita rises and stabilizes as the share of older workers dominate the share of youth in the labor force. In the long run, the demographic transition alone accounts for 16, 14.2 and $10.3 \mathrm{pp}$ decline in the unemployment rates in Iran, Morocco and Egypt. Moreover, it will lead to 70\%, $62 \%$ and $44 \%$ increase in GDP per capita in Iran, Morocco and Egypt, hence faster demographic transition is associated with higher GDP per capita.

We use the cost for capital mobilisation as a proxy for financial sector efficiency, and develop two different scenarios for the financial sector development. Our results suggest that financial efficiency improvements lead to better economic performance in terms of higher GDP per capita and lower unemployment rates in the case of an inevitable demographic change in MENA region. If the financial sector succeeds to reduce the investment cost by half in each decade it will lead to at least $3 \mathrm{pp}$ fall in total unemployment rate by 2100 . Of course the gain is much higher for younger age groups and can reach 8.3 pp for those of ages between 15 to 24 . Thus, we show that the unemployment rate volatility is the highest for the youngest age group, who just entered the labor force, and although the effect of a demographic shift always dominates the effect of a financial market improvement, the size of the effect changes according to the depth of the reform in the financial sector. 


\section{Appendices}

\section{A The demographic shift parameters}

Table 5: Demographic parameters

\begin{tabular}{|c|c|c|c|c|c|c|c|c|c|c|c|}
\hline $\mathrm{t}$ & 2000 & 2010 & 2020 & 2030 & 2040 & 2050 & 2060 & 2070 & 2080 & 2090 & 2100 \\
\hline \multicolumn{12}{|c|}{ Iran } \\
\hline$Z_{0, t}$ & 4.489 & 4.672 & 3.11 & 3.768 & 3.246 & 2.487 & 2.63 & 2.473 & 2.106 & 2.106 & 2.046 \\
\hline$\beta_{1, t}$ & 0.927 & 0.999 & 0.99 & 0.985 & 0.987 & 0.987 & 0.987 & 0.989 & 0.99 & 0.99 & 0.992 \\
\hline$\beta_{2, t}$ & 0.956 & 0.998 & 0.995 & 0.988 & 0.987 & 0.989 & 0.99 & 0.99 & 0.991 & 0.992 & 0.993 \\
\hline$\beta_{3, t}$ & 0.929 & 0.992 & 0.963 & 0.982 & 0.983 & 0.984 & 0.987 & 0.988 & 0.989 & 0.991 & 0.991 \\
\hline$\beta_{4, t}$ & 0.875 & 0.895 & 0.942 & 0.956 & 0.962 & 0.964 & 0.969 & 0.973 & 0.976 & 0.979 & 0.981 \\
\hline
\end{tabular}

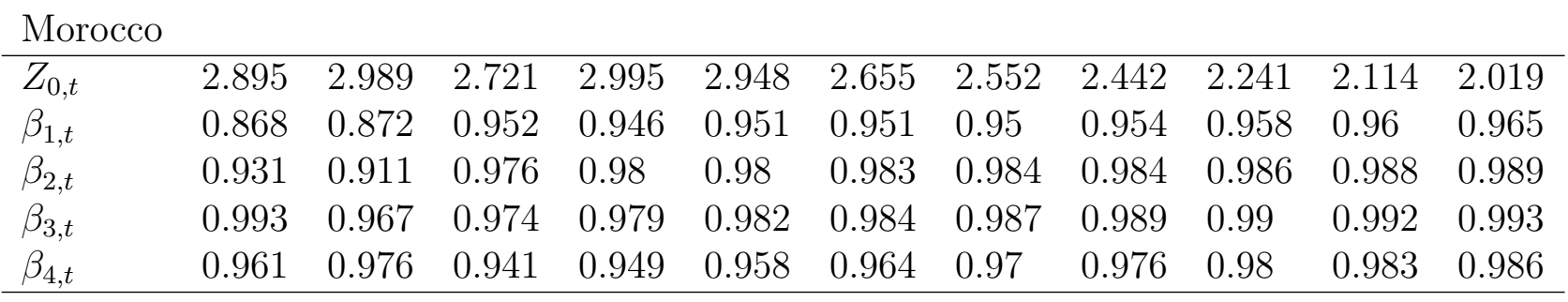

\begin{tabular}{llllllllllll} 
Egypt & & & & & & & & & & & \\
\hline$Z_{0, t}$ & 3.313 & 3.929 & 3.868 & 5.06 & 5.437 & 5.527 & 6.082 & 6 & 5.937 & 5.884 & 5.661 \\
$\beta_{1, t}$ & 0.936 & 0.971 & 0.966 & 0.967 & 0.974 & 0.976 & 0.978 & 0.982 & 0.985 & 0.987 & 0.989 \\
$\beta_{2, t}$ & 0.984 & 0.986 & 0.988 & 0.989 & 0.991 & 0.992 & 0.993 & 0.995 & 0.996 & 0.996 & 0.997 \\
$\beta_{3, t}$ & 0.958 & 0.968 & 0.981 & 0.981 & 0.982 & 0.987 & 0.988 & 0.99 & 0.993 & 0.994 & 0.996 \\
$\beta_{4, t}$ & 0.877 & 0.886 & 0.901 & 0.914 & 0.926 & 0.935 & 0.947 & 0.957 & 0.964 & 0.972 & 0.978 \\
\hline \hline
\end{tabular}

Note: The value of $Z_{0, t}$ are calculated by normalizing the size of the youngest cohort in 1960 (i.e. $Z_{0,1960}=1$ )

The growth rate of the population, Figure 5, is a decreasing fonction, although for Iran and Morocco we observe a slight take off in the final periods of the simulation. 
Figure 4: Population dynamics by age group and total Iran
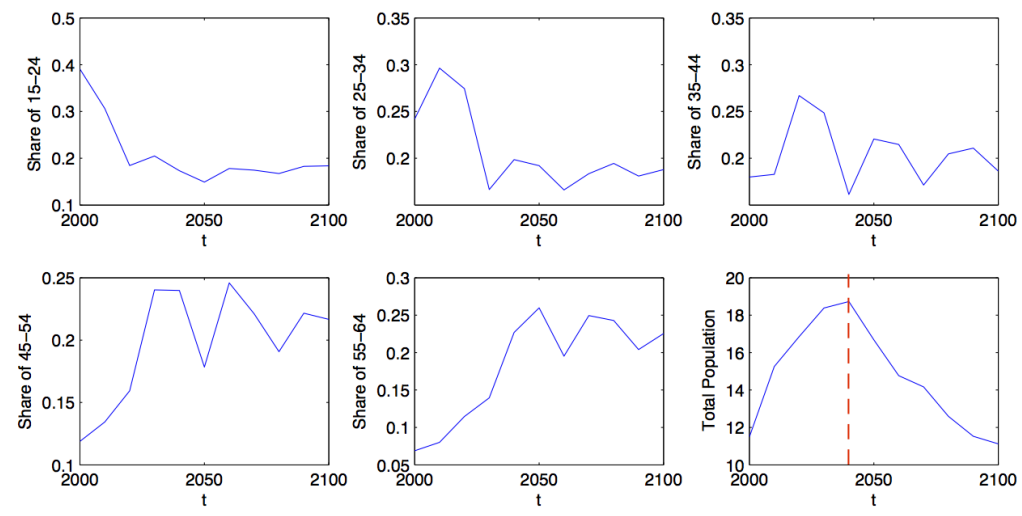

Morocco
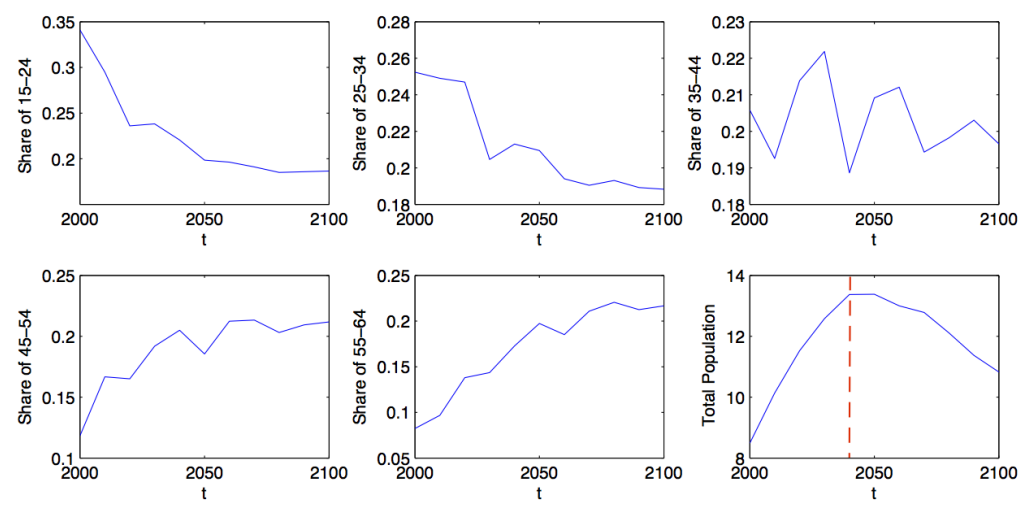

Egypt
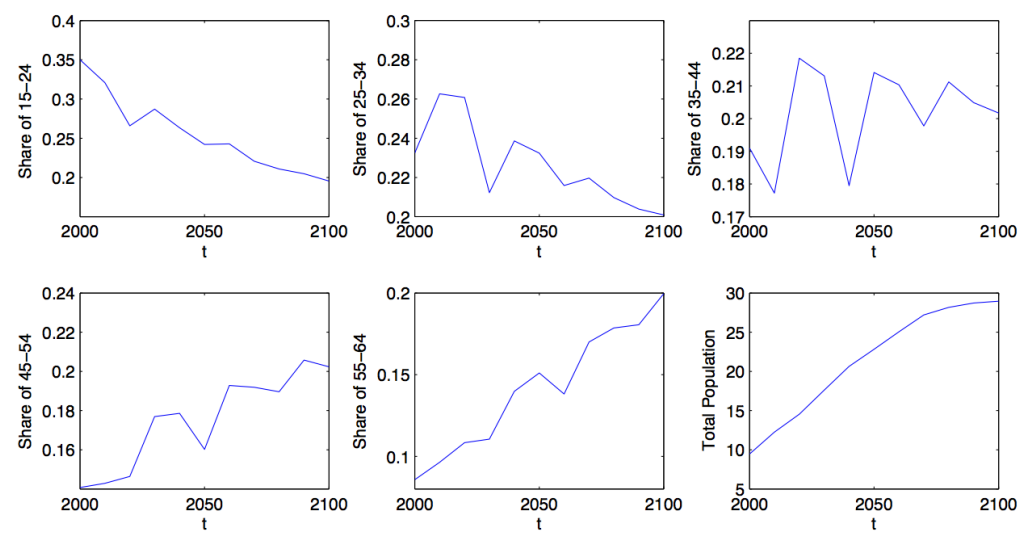

Note: Population of each age group is represented as its share in total active population (Authors' calculations based on UN data set) 
Figure 5: Active population growth rate Iran
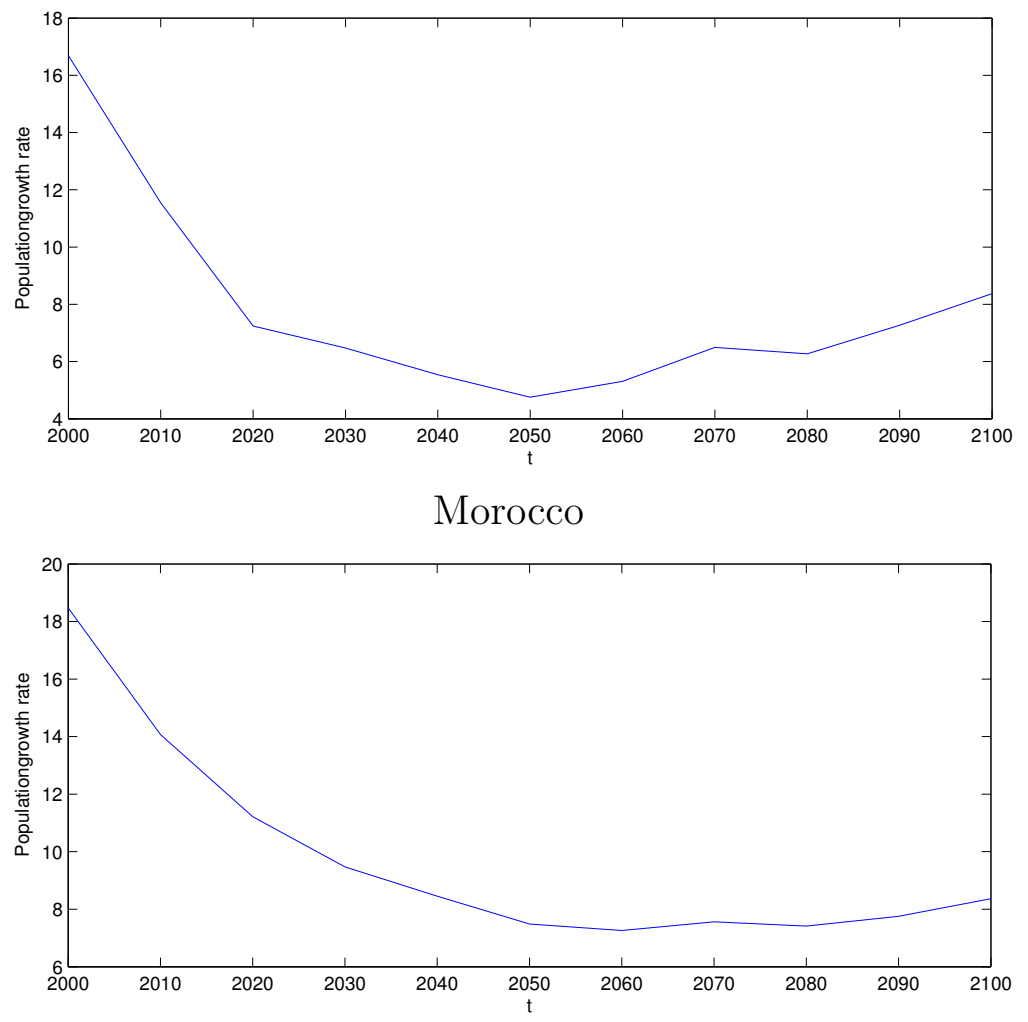

Egypt

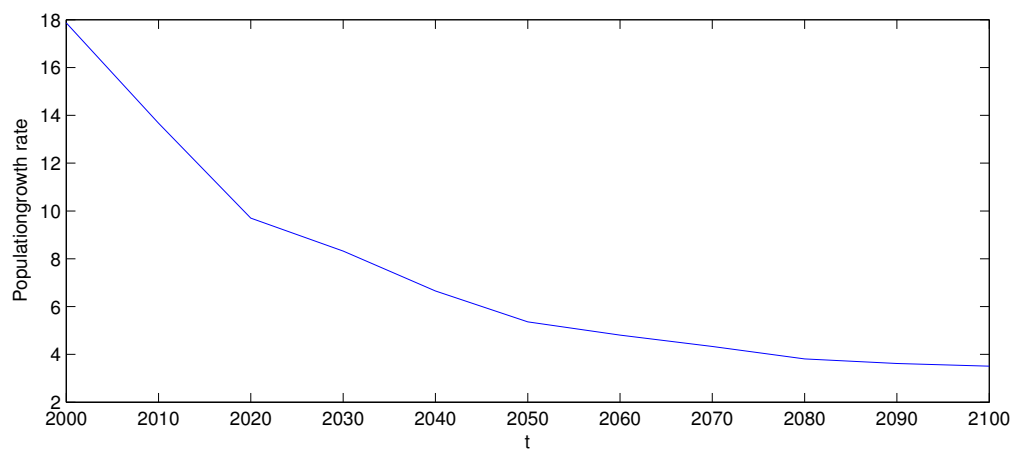




\section{B Robustness check for cost of investment}

In this appendix we show that our results are robust to the initial value of $(1-\varphi)$. In order to do so, we suppose the initial value of $(1-\varphi)$ to be 0.1 instead of 0.2 , which means that the cost of allocating capital is $10 \%$ in our baseline scenario, the definition of High and Low scenario remains the same, the value of $(1-\varphi)$ in each case is reported in Table 6 .

Table 6: The value of $(1-\varphi)$ or the cost of capital accumulation under different scenarios

\begin{tabular}{lrrrrrrrrrr}
\hline \hline Period & 1 & 2 & 3 & 4 & 5 & 6 & 7 & 8 & 9 & 10 \\
\hline Baseline & 0.1 & 0.1 & 0.1 & 0.1 & 0.1 & 0.1 & 0.1 & 0.1 & 0.1 & 0.1 \\
High & 0.1 & 0.05 & 0.025 & 0.0125 & 0.0062 & 0.0031 & 0.00156 & 0.00078 & 0.00039 & 0.00019 \\
Low & 0.1 & 0.095 & 0.090 & 0.085 & 0.081 & 0.077 & 0.073 & 0.069 & 0.066 & 0.063 \\
\hline \hline
\end{tabular}

The results qualitatively, remain the same, although the initial steady state changes slightly since the initial cost of capital is not the same. The simulation results for Iran are reported in Figures 6, 7, 8, 9, 10, 11, 12 and 13. ${ }^{14}$

Figure 6: GDP level evolution (percentage deviation from the initial steady state) for Iran

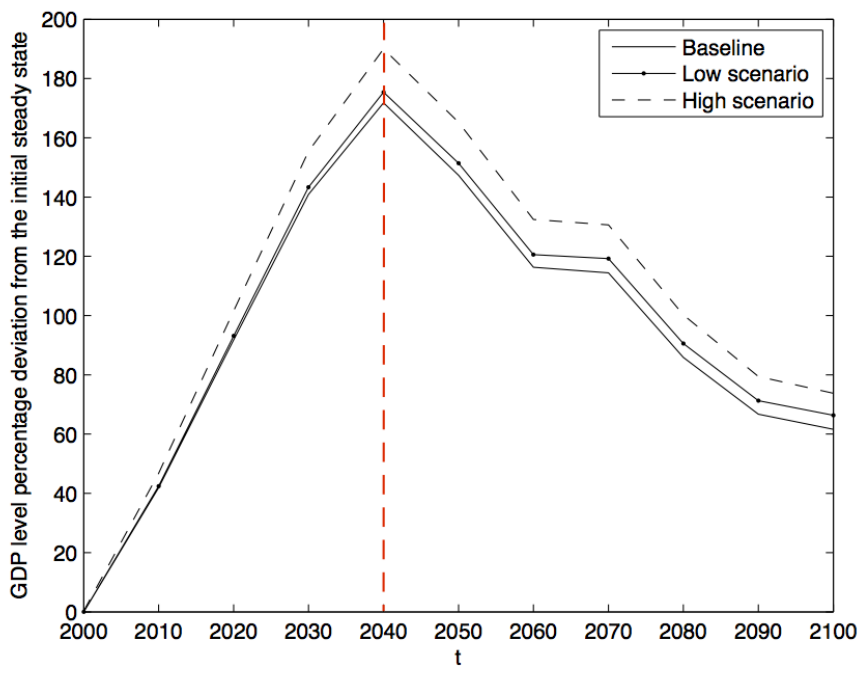

\footnotetext{
${ }^{14}$ We can perform the same exercise for Morocco and Egypt, the results remain the same.
} 
Figure 7: GDP per capita evolution (percentage deviation from the initial steady state) for Iran

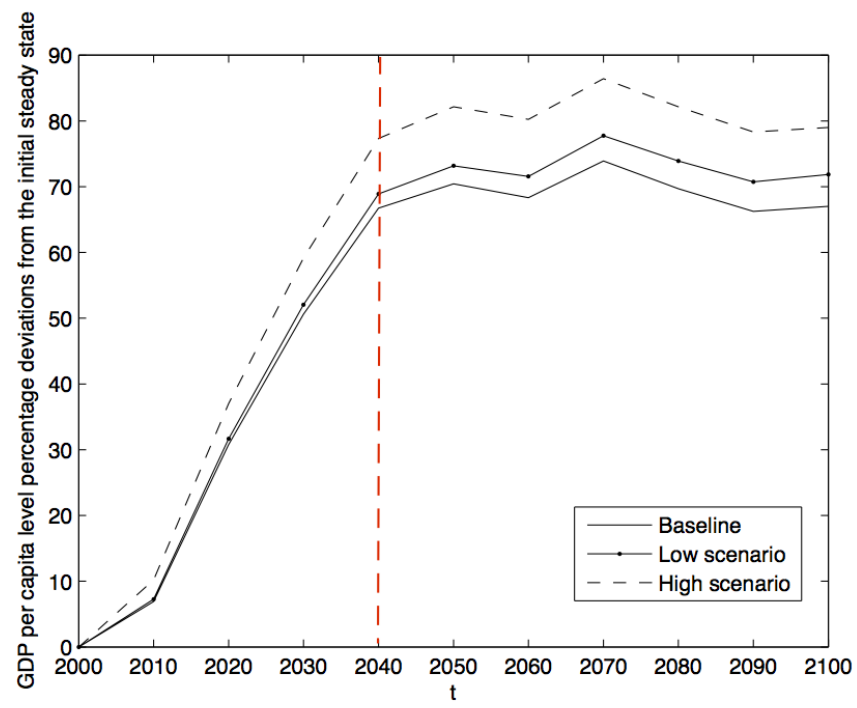

Figure 8: Total unemployment rate evolution for Iran

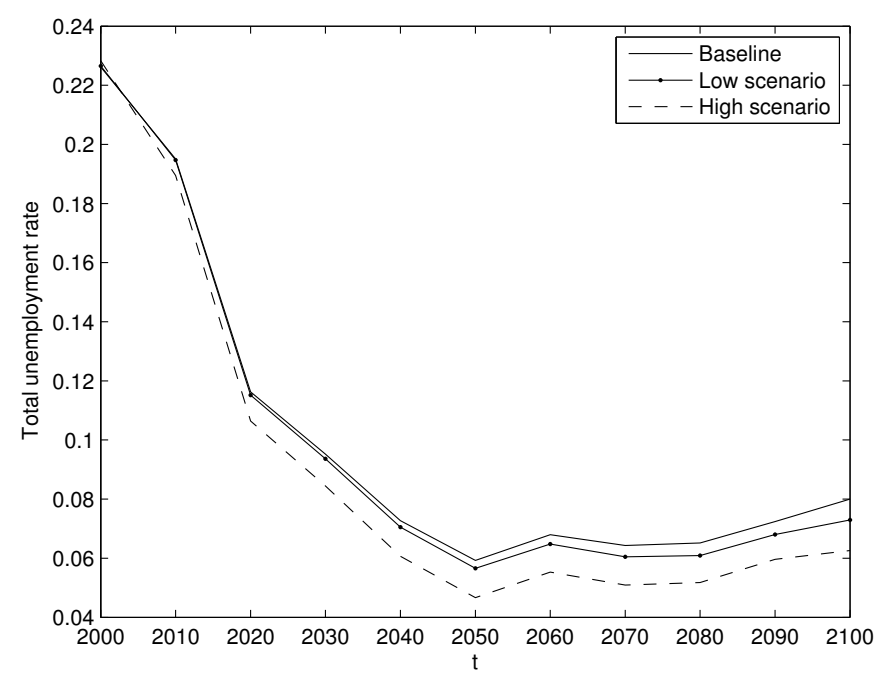


Figure 9: Unemployment rate evolution by age after the demographic shift for Iran

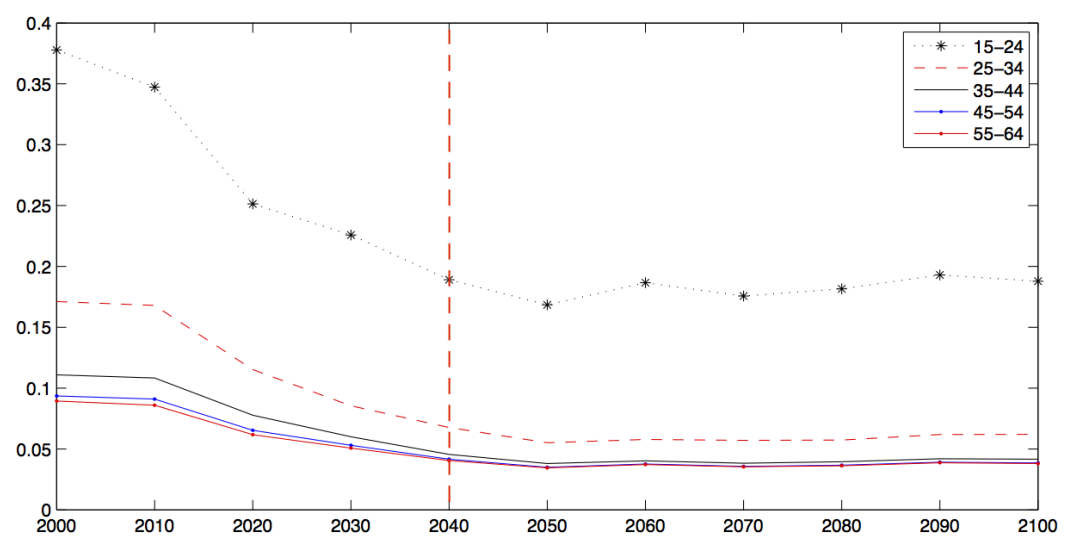

Figure 10: Total savings evolution, percentage deviation from the initial steady state for Iran

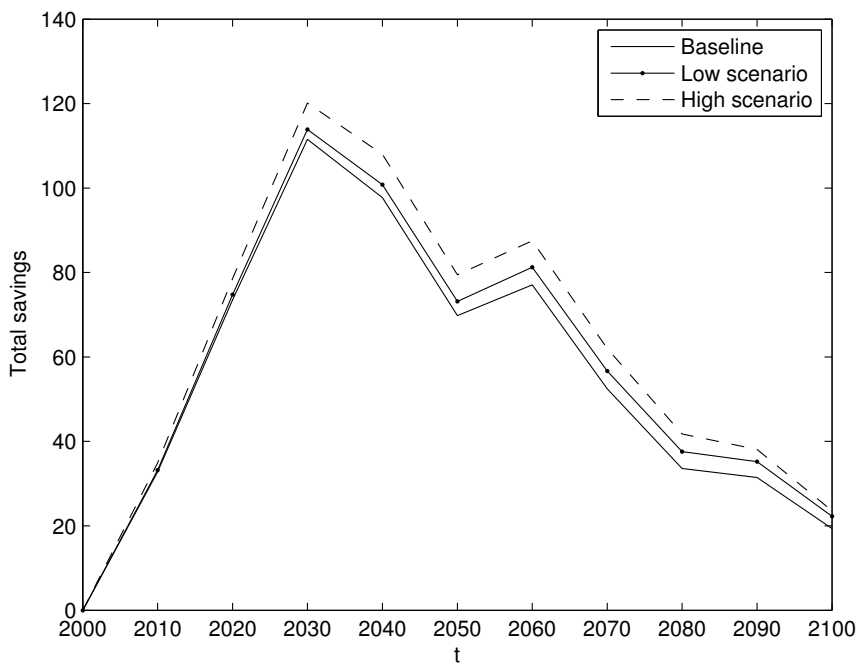


Figure 11: Savings per capita evolution by age for Iran
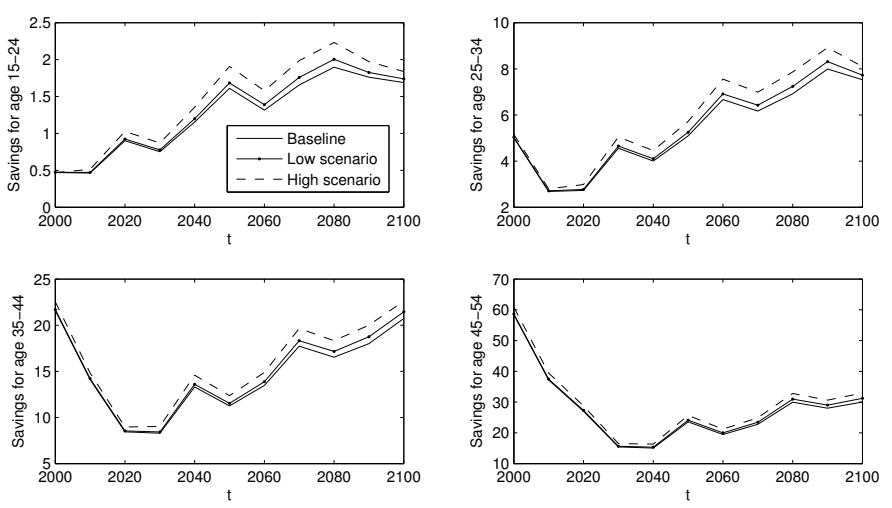

Note: Savings per capita for different age groups, according to model's assumptions, the savings is nul for the last age group (55-64)

Figure 12: Wage evolution by age for Iran
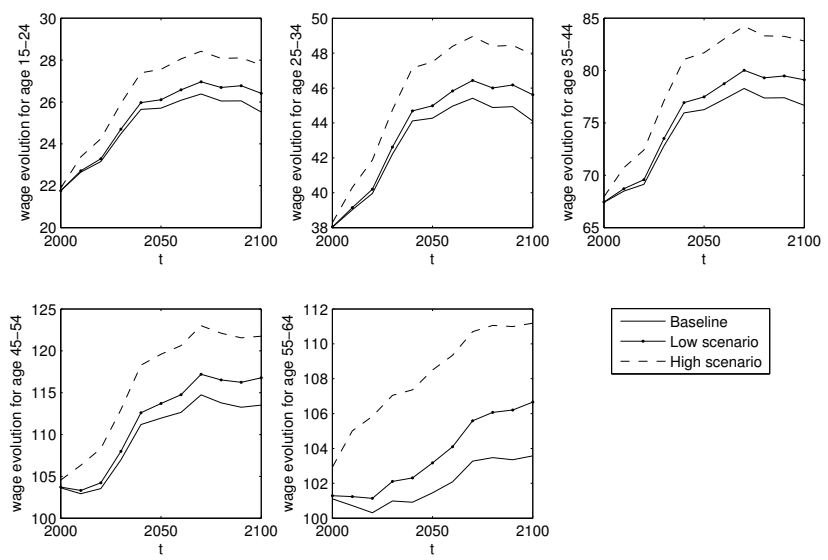

- Baseline
- Low scenario - - - High scenario 
Figure 13: Interest rate evolution for Iran

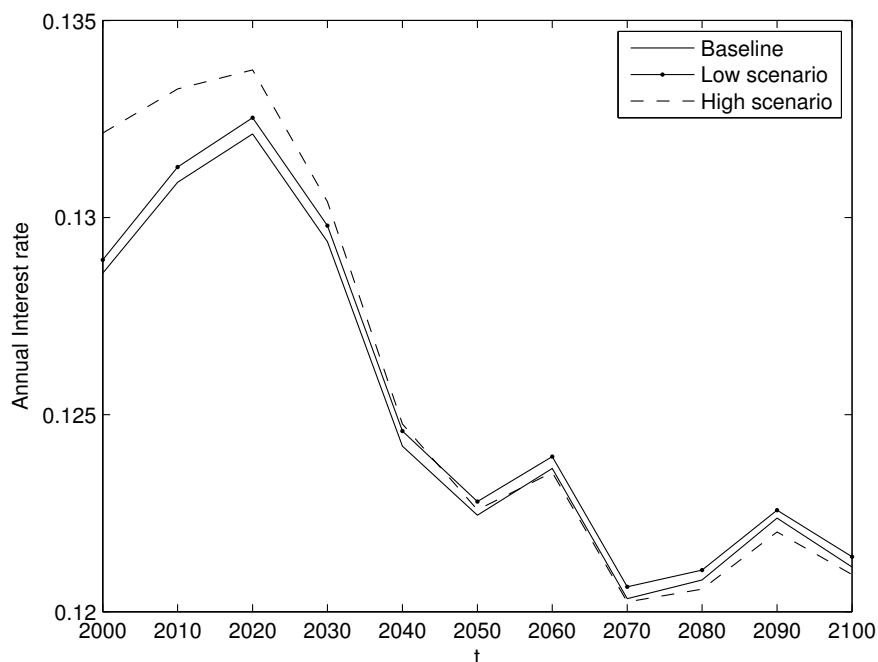




\section{Robustness check, constant human capital}

One may argue that our results are merely a mechanical response to the different age specific human capital, reported in Table 1.

In this Appendix we perform the simulations for Morocco, and suppose a constant human capital for all age groups, i.e. $h_{i}=2.5 \forall i=1, \ldots, 4$ The simulation results are reported in Figures 14, 15, 16, 17, 18, 19 and 20. ${ }^{15}$

Figure 14: GDP level evolution (percentage deviation from the initial steady state)

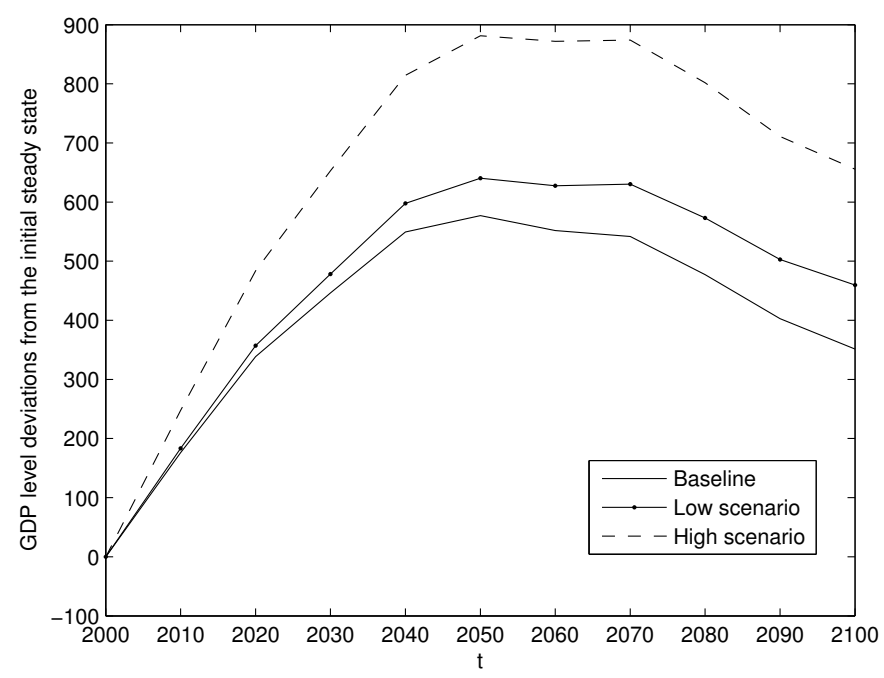

\footnotetext{
${ }^{15}$ We can perform the same exercise for Iran or Egypt the results remain the same.
} 
Figure 15: GDP per capita evolution (percentage deviation from the initial steady state)

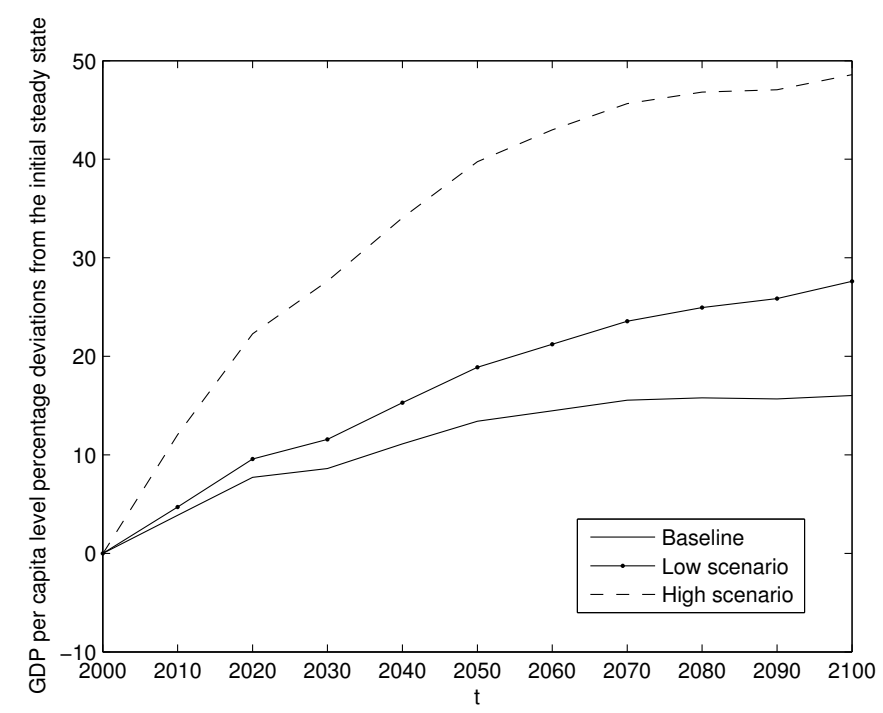

Figure 16: Total unemployment rate evolution

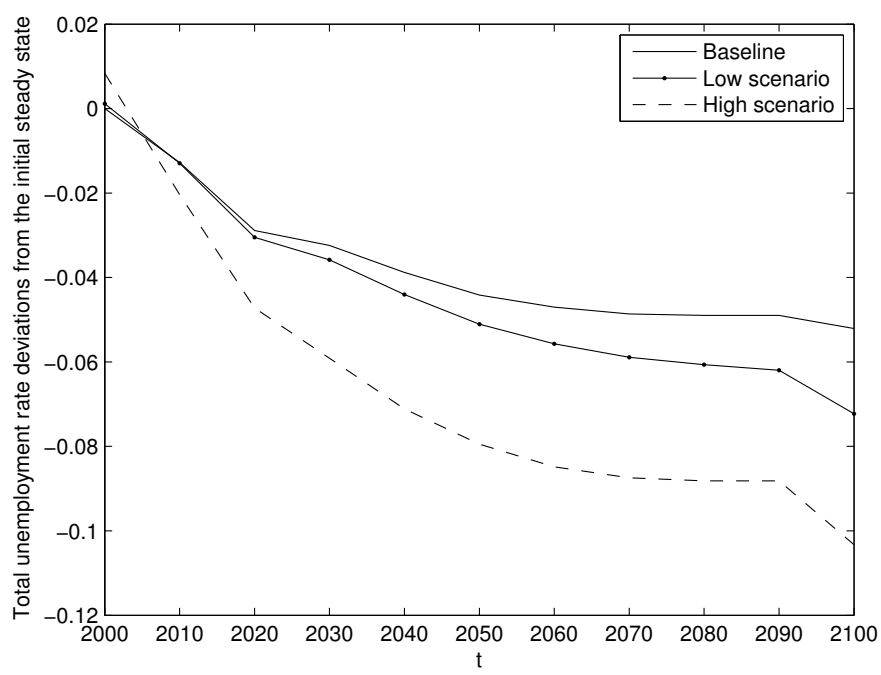


Figure 17: Unemployment rate evolution by age after the demographic shift

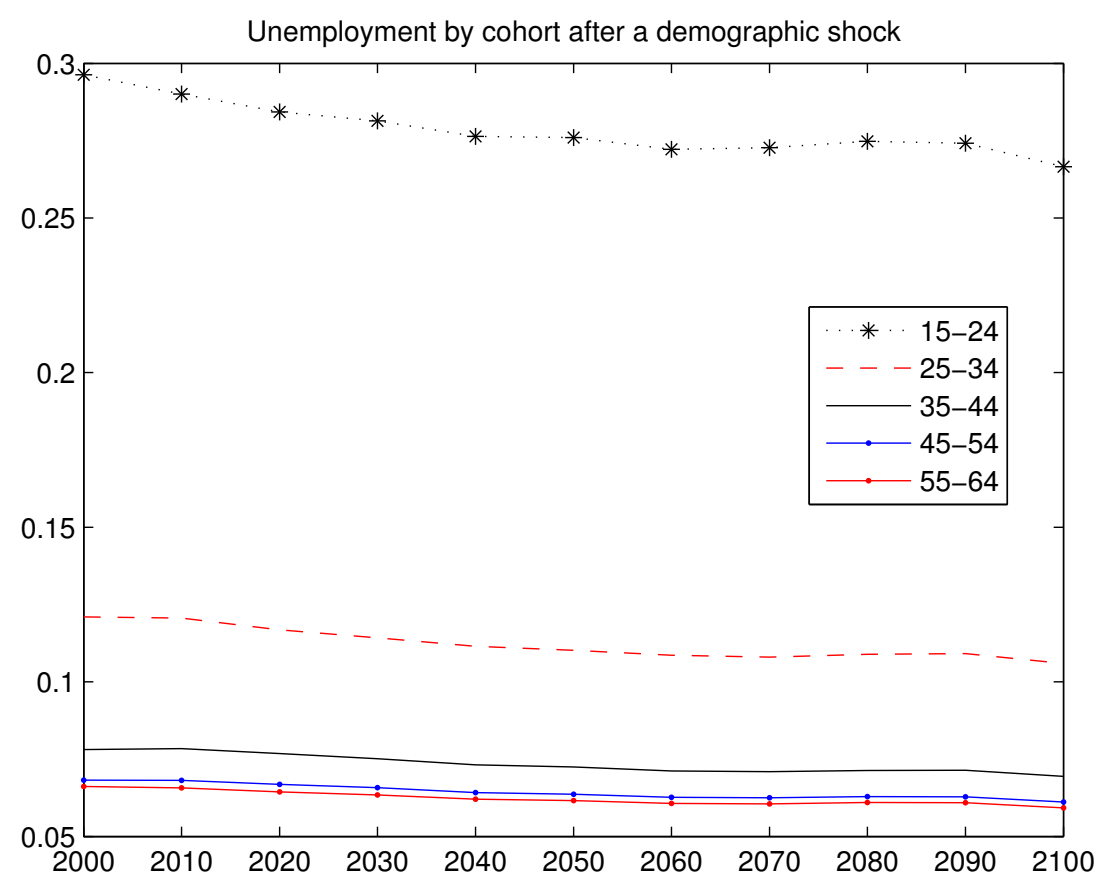

Figure 18: Total savings evolution, percentage deviation from the initial steady state

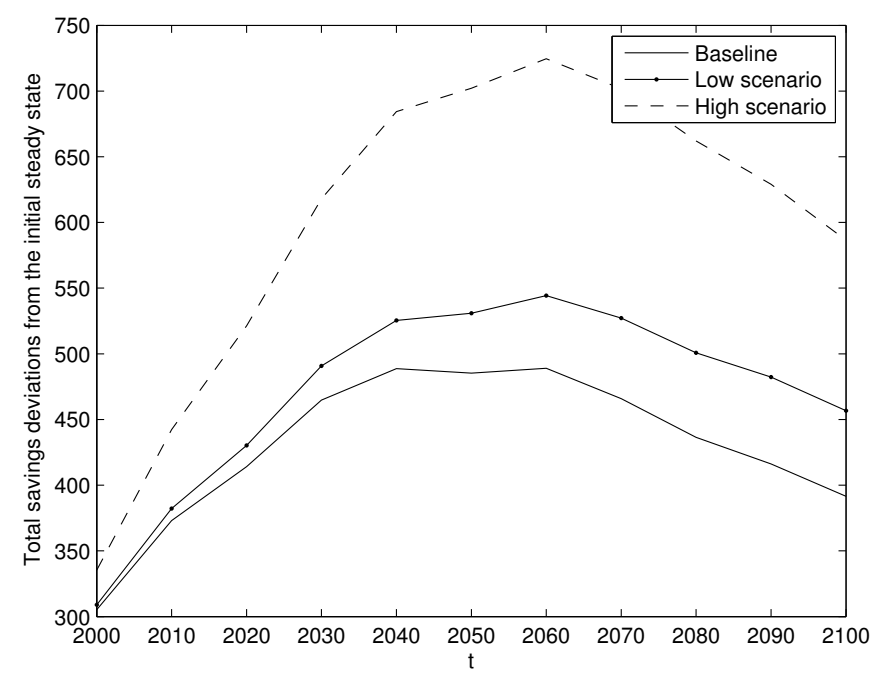


Figure 19: Wage evolution by age
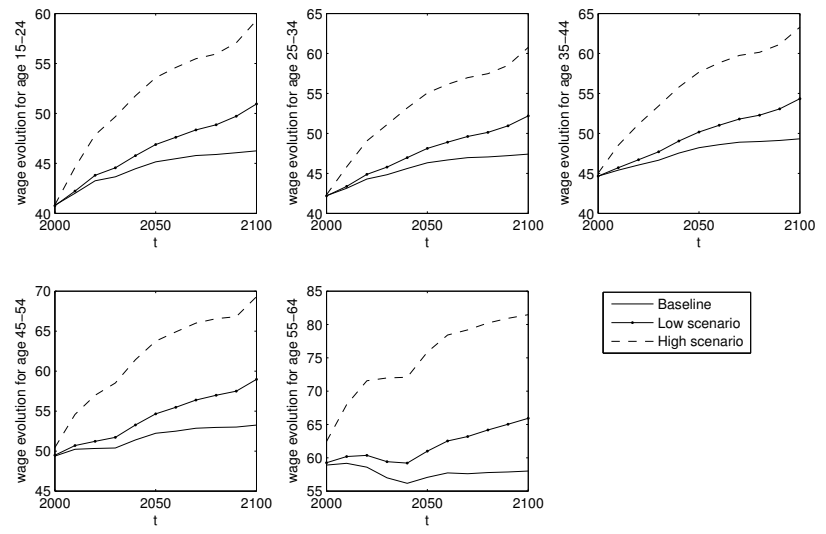

\begin{tabular}{|c|}
\hline Baseline \\
\hline - Low scenario \\
--- High scenario \\
\hline
\end{tabular}

Figure 20: Interest rate evolution

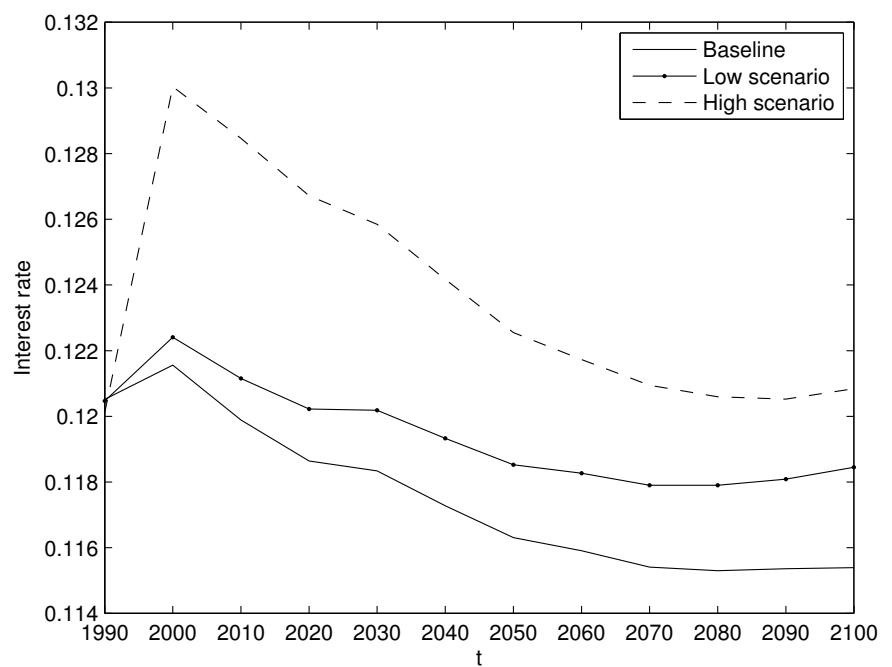




\section{References}

Abel, A. B. (2003). The effects of a baby boom on stock prices and capital accumulation in the presence of social security. Econometrica, 71(2):551-578.

Arcand, J. L., Berkes, E., and Panizza, U. (2015). Too much finance? Journal of Economic Growth, 20(2):105-148.

Assaad, R. A., Hendy, R., Lassassi, M., and Yassin, S. (2018). Explaining the mena paradox: Rising educational attainment, yet stagnant female labor force participation.

Barro, R. J. and Lee, J. W. (2013). A new data set of educational attainment in the world, 1950-2010. Journal of development economics, 104:184-198.

Ben Naceur, S. and Ghazouani, S. (2007). Stock markets, banks, and economic growth: Empirical evidence from the mena region. Research in International Business and Finance, 21(2):297-315.

Ben Naceur, S., Ghazouani, S., and Omran, M. (2008). Does stock market liberalization spur financial and economic development in the MENA region? Journal of Comparative Economics, 36(4):673-693.

Bloom, D., Canning, D., and Sevilla, J. (2003). The demographic dividend: A new perspective on the economic consequences of population change. Rand Corporation.

Bloom, D. E. and Canning, D. (2004). Global demographic change: Dimensions and economic significance. Technical report, National Bureau of Economic Research.

Bloom, D. E., Kuhn, M., and Prettner, K. (2017). Africa's prospects for enjoying a demographic dividend. Journal of Demographic Economics, 83(1):63-76.

Börsch-Supan, A., Ludwig, A., and Winter, J. (2006). Ageing, pension reform and capital flows: A multi-country simulation model. Economica, 73(292):625-658.

Boucekkine, R., De la Croix, D., and Licandro, O. (2002). Vintage human capital, demographic trends, and endogenous growth. Journal of Economic Theory, 104(2):340-375.

Chakraborty, S. (2004). Endogenous lifetime and economic growth. Journal of Economic Theory, 116(1):119-137. 
D'Albis, H. (2007). Demographic structure and capital accumulation. Journal of Economic Theory, 132(1):411-434.

de la Croix, D., Pierrard, O., and Sneessens, H. R. (2013). Aging and pensions in general equilibrium: Labor market imperfections matter. Journal of Economic Dynamics and Control, 37(1):104 - 124.

Demirguc-Kunt, A., Klapper, L., Singer, D., Ansar, S., and Hess, J. (2018). The Global Findex Database 2017: Measuring financial inclusion and the fintech revolution. The World Bank.

Diamond, P. A. (1981). Mobility costs, frictional unemployment, and efficiency. The Journal of Political Economy, pages 798-812.

Favero, C., Gozluklu, . A. E., and Yang, . H. (2015). Demographics and the behavior of interest rates. Working papers, Warwick Business School, Finance Group.

Favero, C. A., Gozluklu, A. E., and Tamoni, A. (2011). Demographic trends, the dividend-price ratio, and the predictability of long-run stock market returns. Journal of Financial and Quantitative Analysis, 46(05):1493-1520.

Geanakoplos, J., Magill, M., and Quinzii, M. (2004). Demography and the longrun predictability of the stock market. Brookings Papers on Economic Activity, 2004(1):241-325.

Greenwood, J., Sanchez, J. M., and Wang, C. (2013). Quantifying the impact of financial development on economic development. Review of Economic Dynamics, 16(1):194-215.

Hagedorn, M. and Manovskii, I. (2008). The cyclical behavior of equilibrium unemployment and vacancies revisited. American Economic Review, 98(4):1692-1706.

Heijdra, B. J. and Ligthart, J. E. (2006). The macroeconomic dynamics of demographic shocks. Macroeconomic Dynamics, 10(3):349-370.

Heijdra, B. J. and Mierau, J. O. (2011). The individual life cycle and economic growth: an essay on demographic macroeconomics. De Economist, 159(1):63-87.

Heijdra, B. J. and Reijnders, L. S. (2016). Human capital accumulation and the macroeconomy in an ageing society. De Economist, 164(3):297-334.

Lagerlöf, N.-P. (2006). The Galor-Weil model revisited: A quantitative exercise. Review of Economic dynamics, 9(1):116-142. 
Lee, R. and Mason, A. (2007). Population aging, wealth, and economic growth: demographic dividends and public policy. Background Paper for the World Economic and Social Survey. New York: United Nations, Department of Economic and Social Affairs.

Leibenstein, H. (1966). Allocative efficiency vs." x-efficiency". The American Economic Review, 56(3):392-415.

Lesmond, D. A., Ogden, J. P., and Trzcinka, C. A. (1999). A new estimate of transaction costs. Review of Financial Studies, 12(5):1113-1141.

Liao, P.-J. (2011). Does demographic change matter for growth? European Economic Review, 55(5):659-677.

Martins, J. O., Gonand, F., Antolin, P., de la Maisonneuve, C., and Yoo, K.-Y. (2005). The impact of ageing on demand, factor markets and growth.

Mason, A. (2005). Demographic transition and demographic dividends in developed and developing countries. In United Nations expert group meeting on social and economic implications of changing population age structures, volume 31. Citeseer.

Mortensen, D. T. and Pissarides, C. A. (1994). Job creation and job destruction in the theory of unemployment. The review of economic studies, 61(3):397-415.

Pagano, M. (1993). Financial markets and growth: An overview. European Economic Review, 37(2-3):613-622.

Pissarides, C. A. (1985). Short-run equilibrium dynamics of unemployment, vacancies, and real wages. The American Economic Review, 75(4):676-690.

Sibai, A., Rizk, A., and Kronfol, N. (2014). Ageing in the arab region: Trends, implications and policy options. Center for Studies on Aging (CSA), ESCWA and UNFPA. Retrieved from http://csa. org. lb/cms/assets/csa\% 20publications/unfpa, 20.

Skirbekk, V. (2004). Age and individual productivity: A literature survey. Vienna Yearbook of Population Research, 2(1):133-154.

United Nations, Department of Economic and Social Affairs, Population Division (2019). World population prospects 2019: Highlights (st/esa/ser.a/423).

Yaari, M. E. (1965). Uncertain lifetime, life insurance, and the theory of the consumer. The Review of Economic Studies, 32(2):137-150. 